University of Nebraska - Lincoln

DigitalCommons@University of Nebraska - Lincoln

Adaptive divergence despite strong genetic drift: genomic analysis of the evolutionary mechanisms causing genetic differentiation in the island fox (Urocyon littoralis)

W. Chris Funk

Robert E. Lovich

Paul A. Hohenlohe

Courtney A. Hofman

Scott A. Morrison

See next page for additional authors

Follow this and additional works at: https://digitalcommons.unl.edu/usnavyresearch

This Article is brought to you for free and open access by the U.S. Department of Defense at

DigitalCommons@University of Nebraska - Lincoln. It has been accepted for inclusion in U.S. Navy Research by an authorized administrator of DigitalCommons@University of Nebraska - Lincoln. 


\section{Authors}

W. Chris Funk, Robert E. Lovich, Paul A. Hohenlohe, Courtney A. Hofman, Scott A. Morrison, T. Scott Sillett, Cameron K. Ghalambor, Jesus E. Maldonado, Torben C. Rick, Mitch D. Day, Nicholas R. Polato, Sarah W.

Fitzpatrick, Timothy J. Coonan, Kevin R. Crooks, Adam Dillon, David K. Garcelon, Julie L. King, Christina L. Boser, Nicholas Gould, and William F. Andelt 


\title{
Adaptive divergence despite strong genetic drift: genomic analysis of the evolutionary mechanisms causing genetic differentiation in the island fox (Urocyon littoralis)
}

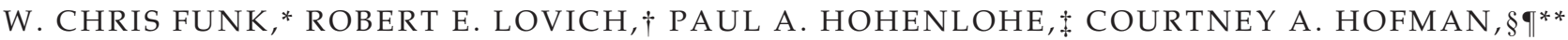 \\ SCOTT A. MORRISON $\uparrow \dagger$ T. SCOTT SILLETT, + CAMERON K. GHALAMBOR,*

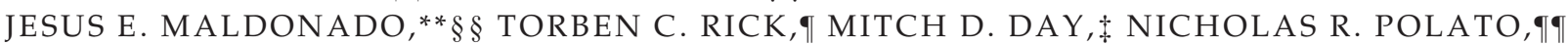 \\ SARAH W. FITZPATRICK, $* * *$ TIMOTHY J. COONAN, $\uparrow+\uparrow$ KEVIN R. CROOKS, $+\$$

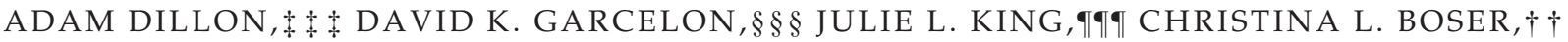 \\ NICHOLAS GOULD**** and WILLIAM F. ANDELT $\$+\$$ \\ *Department of Biology, Graduate Degree Program in Ecology, Colorado State University, 1878 Campus Delivery, Fort Collins, \\ CO 80523, USA, †Naval Facilities Engineering Command Southwest, 1220 Pacific Highway, San Diego, CA 92132, USA, \\ $\$$ Department of Biological Sciences, Institute for Bioinformatics and Evolutionary Studies, University of Idaho, Moscow, ID \\ 83844, USA, §Department of Anthropology, University of Maryland, College Park, MD 20742, USA, 9Program in Human \\ Ecology and Archaeobiology, Department of Anthropology, National Museum of Natural History, Smithsonian Institution, \\ Washington, DC 20013-7012, USA, **Center for Conservation and Evolutionary Genetics, Smithsonian Conservation Biology \\ Institute, National Zoological Park, Washington, DC 20008, USA, ††The Nature Conservancy, San Francisco, CA 94105, USA, \\ $\$$ Migratory Bird Center, Smithsonian Conservation Biology Institute, National Zoological Park, MRC 5503, Washington, DC \\ 20013-7012, USA, §§Department of Vertebrate Zoology, National Museum of Natural History, Smithsonian Institution, \\ Washington, DC 20013-7012, USA, Ф甲Department of Ecology and Evolutionary Biology, Cornell University, Ithaca, NY 14850, \\ USA, ${ }^{* * *}$ Kellogg Biological Station, Department of Integrative Biology, Michigan State University, Hickory Corners, MI 49060, \\ USA, ††NAtional Park Service, Channel Islands National Park, 1901 Spinnaker Drive, Ventura, CA 93001, USA, \\ +t+Department of Fish, Wildife and Conservation Biology, Colorado State University, 1474 Campus Delivery, Fort Collins, CO \\ 80523, USA, §§§Institute for Wildlife Studies, P.O. Box 1104, Arcata, CA 95518, USA, qq⿴Catalina Island Conservancy, P.O. \\ Box 2739, Avalon, CA 90704, USA, ${ }^{* * * * F i s h e r i e s, ~ W i l d l i f e ~ a n d ~ C o n s e r v a t i o n ~ B i o l o g y, ~ N o r t h ~ C a r o l i n a ~ S t a t e ~ U n i v e r s i t y, ~ T u r n e r ~}$ \\ House, Box 7646, Raleigh, NC 27695-7646, USA
}

\begin{abstract}
The evolutionary mechanisms generating the tremendous biodiversity of islands have long fascinated evolutionary biologists. Genetic drift and divergent selection are predicted to be strong on islands and both could drive population divergence and speciation. Alternatively, strong genetic drift may preclude adaptation. We conducted a genomic analysis to test the roles of genetic drift and divergent selection in causing genetic differentiation among populations of the island fox (Urocyon littoralis). This species consists of six subspecies, each of which occupies a different California Channel Island. Analysis of 5293 SNP loci generated using Restriction-site Associated DNA (RAD) sequencing found support for genetic drift as the dominant evolutionary mechanism driving population divergence among island fox populations. In particular, populations had exceptionally low genetic variation, small $N_{\mathrm{e}}$ (range=2.1-89.7; median $=19.4$ ), and significant genetic signatures of bottlenecks. Moreover, islands with the lowest genetic variation (and, by inference, the strongest historical genetic drift) were most genetically differentiated from mainland grey foxes, and vice versa, indicating genetic drift drives genome-wide divergence. Nonetheless, outlier tests
\end{abstract}


identified 3.6-6.6\% of loci as high $F_{\mathrm{ST}}$ outliers, suggesting that despite strong genetic drift, divergent selection contributes to population divergence. Patterns of similarity among populations based on high $F_{\mathrm{ST}}$ outliers mirrored patterns based on morphology, providing additional evidence that outliers reflect adaptive divergence. Extremely low genetic variation and small $N_{\mathrm{e}}$ in some island fox populations, particularly on San Nicolas Island, suggest that they may be vulnerable to fixation of deleterious alleles, decreased fitness and reduced adaptive potential.

Keywords: conservation genomics, divergent selection, effective population size, genetic drift, population divergence

Received 15 May 2015; revision received 17 February 2016; accepted 23 February 2016

\section{Introduction}

Islands are global centres of biodiversity and endemism (Stuart et al. 2012), but the evolutionary mechanisms generating this diversity are typically poorly understood (with some notable exceptions, e.g., Losos et al. 1998; Grant \& Grant 2002; Jordan \& Snell 2008). Isolation is a common feature associated with divergence and speciation among island populations (Grant 1998), but ultimately, the processes of genetic drift and/or divergent selection acting on standing genetic variation and new mutations is required for differences to accumulate (Fisher 1930; Wright 1931, 1951). To date, most research on island biodiversity has largely focused on those examples where divergent selection has generated striking cases of adaptive evolution (Losos et al. 1998; Grant \& Grant 2002). However, much less attention has been given to the role of genetic drift in generating differences among isolated islands (Jordan \& Snell 2008). Thus, investigating the joint roles of genetic drift and divergent selection is key for understanding how island populations diverge, thereby generating island biodiversity and endemism.

Genetic drift is expected to be strong in island populations for several reasons. First, many island populations are founded by a small number of individuals whose genetic composition may differ significantly from the source (often continental) population due to random chance (Martínez-Solano \& Lawson 2009; Kolbe et al. 2012). Second, island populations often have small effective population sizes $\left(N_{\mathrm{e}}\right)$. Especially if an island is limited in size, it may have a low carrying capacity and, as a result, a small $N_{\mathrm{e}}$ (Frankham 1998; Eldridge et al. 1999). The third reason is bottlenecks. Like many populations, island populations are likely to experience fluctuations in population size in the course of their history, sometimes resulting in significant population size reductions or bottlenecks (Frankham 1998; Heber et al. 2013). Yet unlike continental populations, isolated island populations may not receive an infusion of genetic variation through gene flow after bottlenecks, resulting in a per- manent reduction in genetic variation (or at least a longterm reduction, as mutation may eventually partially replenish lost genetic variation; Eldridge et al. 1999).

Divergent selection is also expected to be strong among island populations due to high environmental heterogeneity among islands and between islands and the mainland (Weigelt et al. 2013). One potential source of environmental variation on islands is climate, including temperature, precipitation and fog (Fischer \& Still 2007). The specific position of islands relative to ocean currents can have profound effects on their climate (Spalding et al. 2007), as do differences in elevation and topography. Another source of environmental variation among islands is community composition. Island biogeography theory makes the simple but important prediction that larger islands have more species (MacArthur \& Wilson 1967), but even adjacent islands that are the same size may have different species due to climate, microhabitat availability, and random chance of which species end up on which islands (Burns 2007). Thus, both genetic drift and divergent selection can be strong in island populations, which means either or both processes could drive genetic differentiation and population divergence among islands. However, if drift is strong, it may overwhelm selection, precluding adaptive divergence (Wright 1931, 1951).

One of the most iconic island species in the world is the island fox (Urocyon littoralis), a species whose origin, evolution and divergence has fascinated evolutionary biologists for decades (Grinnell et al. 1937; Gilbert et al. 1990; Wayne et al. 1991; Collins 1993; Goldstein et al. 1999; Aguilar et al. 2004). This species is a diminutive, endemic fox sister to the mainland grey fox (Urocyon cinereoargenteus) and is found on six of the eight Channel Islands off the coast of southern California (Fig. 1) (Coonan et al. 2010). Recent archeological and mitogenomic studies have demonstrated that island foxes diverged from their mainland progenitor $\sim 9200$ 7100 years ago and have been on the northern Channel Islands (San Miguel [SMI], Santa Rosa [SRI], and Santa Cruz [SCI]) for at least 7100 years and the southern 


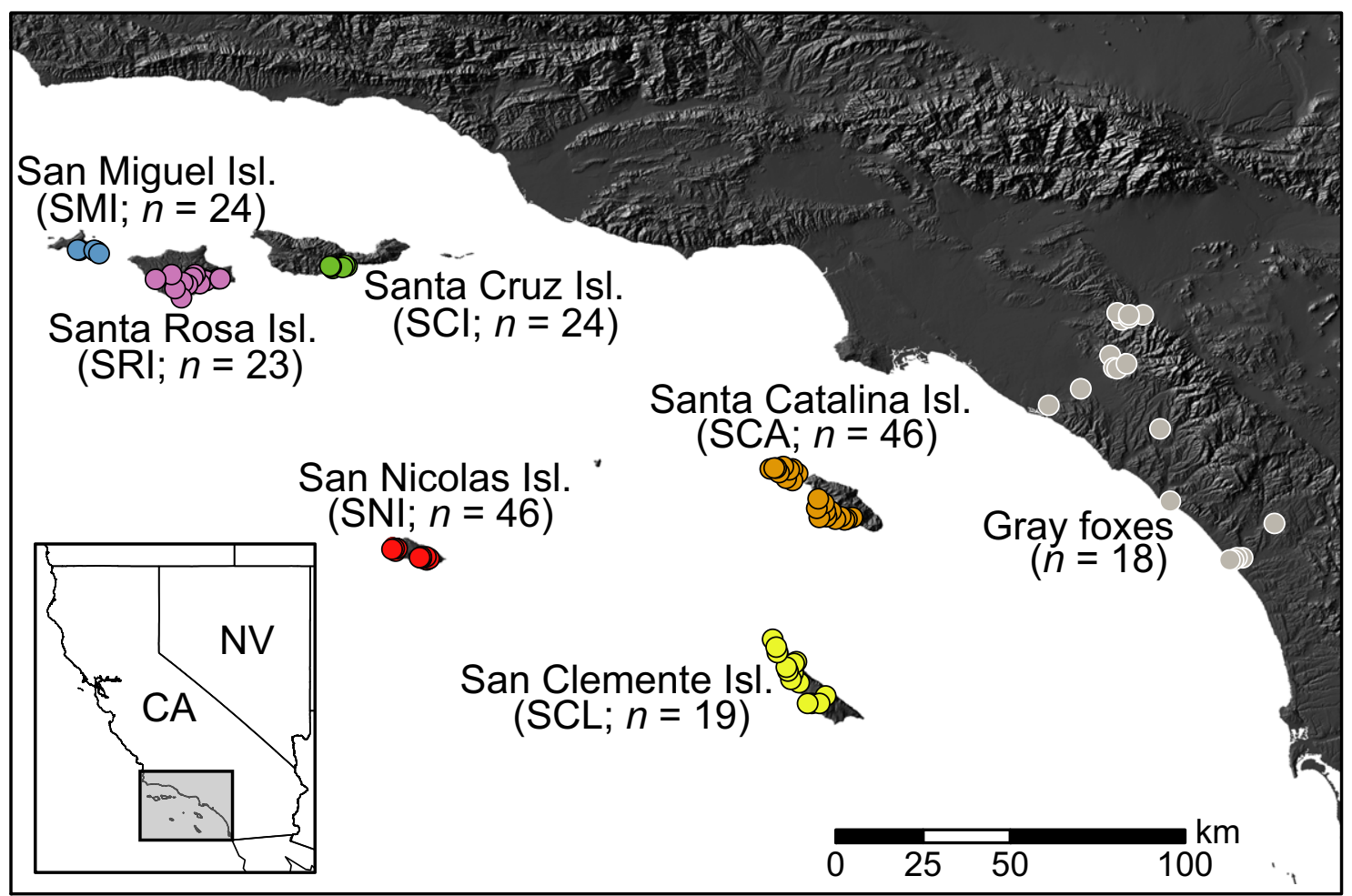

Fig. 1 Map of island fox and grey fox individuals included in genomic analyses. Abbreviations and sample sizes are shown in parentheses. Inset shows location of study area in southern California, USA.

Channel Islands (Santa Catalina [SCA], San Clemente [SCL], and San Nicolas [SNI]) for at least 5000 years (Rick et al. 2009; Hofman et al. 2015). Foxes may have been transported to the Channel Islands by rafting on debris flows or by Native Americans as part of ritual practices, as they are found in formal cemeteries and burials, for their pelts which were used as clothing, and for helping reduce pests (e.g., mice populations) (Rick et al. 2009; Hofman et al. 2015). These studies also suggest a prehistoric, human translocation of island foxes from the northern to the southern Channel Islands based on AMS radiocarbon dates. Earlier morphological and genetic studies described island foxes on each island as a separate subspecies (Grinnell et al. 1937; Gilbert et al. 1990; Wayne et al. 1991; Collins 1993; Goldstein et al. 1999). Although high levels of genetic differentiation have been documented among island fox populations (Aguilar et al. 2004), there is no evidence to date that observed morphological differences among islands are genetically based or adaptive.

Solving the puzzle of high genetic differentiation among island fox populations requires an understanding of their recent population crashes and recovery. In the late 1990s, subspecies on four islands went through severe population bottlenecks (Table 1), leading to their listing as endangered in 2004 under the U.S.
Endangered Species Act (U.S. Fish and Wildlife Service 2004). The three northern island populations crashed because of predation by golden eagles (Aquila chrysaetos), which had colonized the islands due to abundant food provided by feral pigs and sheep (Roemer et al. 2001; Coonan et al. 2010). On SCA, declines were caused by canine distemper virus (CDV), likely introduced by raccoons (Procyon lotor) or dogs (Timm et al. 2009). San Nicolas Island foxes may have dropped to as low as 20 individuals in the 1970s for unknown reasons (Coonan et al. 2010). The only island that has not experienced a recent bottleneck based on intensive island fox population monitoring efforts on all islands is SCL. Populations on each of the northern islands and SCA have recovered over the past decade as the result of intensive and rapid management efforts, including removal of golden eagles, feral pigs, and ungulates, CDV vaccinations, and separate captive breeding programs on each of these islands (Table 1) (Coonan et al. 2010). However, the SNI population of island foxes is small and currently declining (Table 1; Coonan 2015).

Strong genetic drift caused by founder effects and the bottlenecks described above could play an important role in causing high genetic differentiation among island fox populations. In addition, island fox populations are exposed to varying environmental conditions 
Table 1 Population bottleneck year and sizes, current population sizes, sample sizes $(n)$ before and after SNP quality filters for mainland grey foxes and each island fox population

\begin{tabular}{|c|c|c|c|c|c|}
\hline Site & Bottleneck year & Bottleneck size & $\begin{array}{l}\text { Current size } \\
\text { in } 2014\end{array}$ & $\begin{array}{l}n \text { (total } \\
\text { sampled) }\end{array}$ & $\begin{array}{l}n \text { (after } \\
\text { filters) }\end{array}$ \\
\hline Grey foxes & NA & NA & Unknown & 18 & 16 \\
\hline SMI & 1999-2000 & 15 & 470 & 24 & 21 \\
\hline SRI & 1999-2000 & 15 & 826 & 23 & 23 \\
\hline SCI & 1999-2000 & $50-60$ & 2466 & 24 & 24 \\
\hline SCA & 1999 & (>90\% decline) & 1624 & 46 & 43 \\
\hline SCL & NA & NA & 1230 & 19 & 17 \\
\hline SNI & 1970s & $20 ?$ & 263 & 46 & 44 \\
\hline
\end{tabular}

Island fox bottleneck year and bottleneck population size estimates from Coonan et al. (2010). No estimate of the population size is available for Santa Catalina Island during its 1999 bottleneck, but this population is estimated to have declined by $>90 \%$. San Nicolas island foxes may have dropped to as low as 20 individuals in the 1970s. Current adult population size estimates for 2014 from Coonan (2015).

across the Channel Islands archipelago, likely generating divergent selection on top of genetic drift. In particular, SMI and SRI are substantially cooler and wetter than SCI, SCA and SCL because they are nested within different marine ecoregions (Spalding et al. 2007). In addition, island foxes on different islands have significantly different prey bases and diets (Cypher et al. 2014). Finally, exposure to pathogens varies among islands, e.g., CDV in the late 1990s on SCA (Timm et al. 2009). Genetic drift and divergent selection therefore could both be important drivers of divergence among island fox populations, or genetic drift may overwhelm selection, preventing adaptation.

Determining the roles of genetic drift and divergent selection in causing genetic differentiation in island foxes also has direct bearing on conservation and management of this high-profile species of conservation concern. First, understanding the relative importance of these mechanisms is directly relevant to their current legal designation and management as distinct subspecies. Under most definitions of subspecies and Evolutionarily Significant Units (ESUs) - which can receive legal protection under the U.S. Endangered Species Act (ESA), as in the case of island foxes on SMI, SRI, SCI and SCA-adaptive differences, in addition to genomewide genetic differentiation and phenotypic differences, are required (Ryder 1986; Crandall et al. 2000; Funk et al. 2012; Robertson et al. 2014). Thus, knowing whether or not there are adaptive differences among island fox populations is directly relevant to their legal protection as subspecies.

Second, understanding the strength of genetic drift in island fox populations is important for knowing whether loss of genetic variation is a significant threat to their persistence. If extreme bottlenecks have substantially reduced genetic variation in island foxes, this could make these populations vulnerable to both inbreeding depression (Ralls et al. 1979; Ralls \& Ballou 1983; Lacy 1997; Newman \& Pilson 1997; Saccheri et al. 1998) and a reduced ability to adapt to future environmental change (Bürger \& Lynch 1995), such as the predicted warming and drying of southern California in the coming century (Cayan et al. 2008; LaDochy \& Witiw 2012; Cook et al. 2015).

Lastly, understanding divergent selection and adaptive differentiation among island fox populations is relevant to future consideration of genetic rescue as a management strategy (Tallmon et al. 2004; Whiteley et al. 2015). Outbreeding depression rather than genetic rescue could result if a source population is maladapted to the target population (Edmands 2007; Frankham et al. 2011). Thus, understanding patterns of adaptive differentiation among islands will inform predictions about the likelihood that genetic rescue would increase fitness and population sizes.

Our goal here was to use a population genomic approach with single-nucleotide polymorphism (SNP) data generated from Restriction-site Associated DNA (RAD) sequencing to investigate the roles of genetic drift and divergent selection in causing population divergence among island fox populations. Genomics greatly improves our ability to address this question compared to traditional population genetics approaches with small numbers of markers by increasing power to identify loci under selection, providing enough variability in small populations to estimate $N_{e}$ and test for bottlenecks, and improving statistical power and precision. We had four specific aims. First, we characterize the genetic population structure of island foxes. Second, we test the hypothesis that genetic drift contributes to genetic differentiation among populations. Third, we test the hypothesis that divergent selection caused by environmental differences among islands contributes to genetic differentiation among populations. Fourth, we 
characterize patterns of population divergence at neutral vs. any detected adaptive loci. We conclude with a discussion of the conservation implications of our findings.

\section{Methods}

\section{RAD sequencing and genotyping}

We used Restriction-site Associated DNA (RAD) sequencing (Baird et al. 2008) to genotype 182 island foxes and 18 outgroup grey foxes (Goldstein et al. 1999; Hofman et al. 2015) collected between 2008 and 2011. DNA was extracted from blood samples or muscle tissue from road-killed foxes using DNeasy blood and tissue extraction kits (Qiagen, Valencia, CA, USA) following the manufacturer's protocol. We sequenced $18-46$ individuals (median $=24$ individuals) per island (or from the mainland, in the case of grey foxes; Fig. 1 and Table 1).

As there is currently no island fox reference genome, we used a two-step RAD sequencing approach. First, we assembled reference contigs using paired-end sequences from eight individuals at high coverage depth $(\sim 100$ X) (Etter \& Johnson 2012; Hohenlohe et al. 2013). DNA from these individuals was prepared in an individually barcoded RAD library following the method of Etter et al. (2011) using the restriction enzyme SbfI. Next, we selected fragments corresponding to insert sizes of $230-400 \mathrm{bp}$ and sequenced this library in a single $150 \mathrm{bp}$ paired-end Illumina HiSeq lane. After sequencing, we filtered for read quality and presence of a correct barcode and SbfI recognition site, identified and removed PCR duplicates, pooled the data from all individuals, identified loci using STACKS software (Catchen et al. 2011, 2013), and assembled consensus RAD contigs from the overlapping paired-end reads separately at each locus following methods and parameters outlined in Hohenlohe et al. (2013).

We next prepared individually barcoded RAD libraries for the remaining individuals $(n=192)$ as above and sequenced them on an Illumina HiSeq with single-end $100 \mathrm{bp}$ reads at lower depth $(\sim 20 \mathrm{X})$ in a total of four lanes with 47-49 individuals per lane. After filtering reads as above, we aligned these "clean" reads against the reference RAD contigs, removing those loci that did not align uniquely, and called diploid genotypes along the $100 \mathrm{bp}$ stretch using a maximum likelihood statistical method (Hohenlohe et al. 2010a; Catchen et al. 2013). The forward reads from the eight individuals used to assemble contigs were also aligned and genotyped.

This two-step procedure of first assembling reference contigs using paired-end sequencing, followed by aligning single-end reads to reference contigs provides multiple advantages over single-end sequencing alone. First, assembling reference contigs provides a high-confidence reference "genome" for the RAD loci. Longer paired-end reads and contig assembly better distinguish paralogous and duplicate loci and allow for a greater chance of finding functional information about high $F_{\mathrm{ST}}$ outliers with blasting than shorter, single-end contigs (Hohenlohe et al. 2013). Second, alignment of subsequent single-end reads to these reference contigs provides higher-confidence clustering of reads to the correct loci and an additional layer of filtering for the single-end read data (e.g., removing non-RAD sequence, quality filtering, etc.).

After calling SNPs, we performed several additional quality filters. First, we removed any loci for which more than half of the individuals had missing data (Hohenlohe et al. 2010a). Second, for those RAD tags with more than 1 SNP per contig, we only used the first (most $5^{\prime}$ ) SNP per contig, as the choice of which SNP to use per contig did not affect results. For example, there were no biases or statistically significant differences in genetic differentiation or within population genetic variation based on the first vs. latter SNPs. Third, we removed loci with minor allele frequencies $<0.10$, as low frequency alleles may represent PCR errors. Fourth, we removed any individuals with genotypes for $<50 \%$ of loci. Finally, we removed loci with exceptionally high coverage (coverage greater than 2 SD above the mean), as these loci could be paralogs (Emerson et al. 2010).

\section{Data analysis}

Aim 1: characterize population structure. We used several analyses to characterize population structure among island fox and grey fox populations. First, we estimated two different indices of genetic differentiation among all island fox populations and mainland grey foxes: pairwise $F_{\mathrm{ST}}$ and Jost's D (Jost 2008; Verity \& Nichols 2014). Pairwise $F_{\mathrm{ST}}$ estimates and their significance were calculated using 1000 permutations in ARLEQUIN 3.5 (Excoffier et al. 2005) and Jost's D estimates were calculated in GENALEX 6.5 (Peakall \& Smouse 2006, 2012). In addition, we tested the sensitivity of $F_{\mathrm{ST}}$ estimates to our threshold for the allowed level of missing genotypes ( $<50 \%$; see "RAD sequencing and genotyping" section of Methods above) by calculating $F_{\mathrm{ST}}$ again using a more stringent threshold $(<20 \%)$ and then estimating the correlation coefficient between pairwise $F_{\mathrm{ST}}$ estimates calculated with these different thresholds. We also calculated the correlation coefficient between pairwise $F_{\mathrm{ST}}$ and Jost's $D$ estimates.

Secondly, we inferred the number of island fox and grey fox populations using the Bayesian clustering 
algorithm implemented in program STRUCTURE 2.3.4 (Pritchard et al. 2000). STRUCTURE infers the best-supported number of clusters $(K)$ in the sample and the proportion of each individual's genome assigned to each cluster $\left(q_{\mathrm{k}}\right)$. We ran STRUCTURE with an MCMC burn-in of 100000 steps followed by 100000 steps for inference of clustering (Willing et al. 2010) and used the admixture model with correlated allele frequencies. We tracked $\operatorname{LnP}(D)$, the probability of the data given $K$, over the course of the run to ensure that these values had stabilized at the end of the burn-in period. STRUCTURE was run for $K=1-10$ with 10 replicates for each value of $K$. We inferred the best-supported value of $K$ using a combination of mean $\operatorname{LnP}(K)$ and the $\Delta K$ method of Evanno et al. (2005) as implemented in STRUCTURE HARVESTER (Earl \& Vonholdt 2012).

Third, we examined patterns of genetic divergence and similarity using two different analyses. Principal Components Analysis (PCA) was performed with the 'prcomp' package in program $\mathrm{R}$ ( $\mathrm{R}$ Development Core Team 2010). Neighbour-net trees were then inferred using program SPLITSTREE4 (Bryant \& Moulton 2004; Huson \& Bryant 2006). For the Neighbour-net tree analysis, all heterozygous SNPs were coded according to International Union of Pure and Applied Chemistry (IUPAC), uncorrected_P distance was used as the metric, and ambiguous states were treated as average matches. These last two analyses were performed with and without grey foxes to test the sensitivity of patterns of genetic differentiation to inclusion of the outgroup.

Aim 2: test the contribution of genetic drift to genetic differentiation. Two main predictions stem from the hypothesis that genetic drift due to small effective population sizes $\left(N_{\mathrm{e}}\right)$, founder effects, and/or bottlenecks is a significant cause of high genetic differentiation among island fox populations: (i) island fox populations will have low genetic variation (indicating strong historical genetic drift), small $N_{\mathrm{e}}$, and/or evidence of bottlenecks; and (ii) pairwise genetic differentiation between island fox populations and the mainland (grey foxes) will be negatively correlated with indices of historical genetic drift (estimates of within population genetic variation). In other words, following Jordan \& Snell (2008) and Whiteley et al. (2010), we expected high $F_{\mathrm{ST}}$ values when within-population genetic variation was low, and vice versa.

To test the first prediction, we estimated several indices of within-population genetic variation, estimated $N_{\mathrm{e}}$, and tested for bottlenecks. We used four measures to characterize within-population genetic variation for island foxes and grey foxes: observed heterozygosity $\left(H_{\mathrm{o}}\right)$, expected heterozygosity $\left(H_{\mathrm{e}}\right)$, allelic richness $\left(A_{\mathrm{r}}\right)$ and nucleotide diversity $(\pi) . H_{\mathrm{o}}, H_{\mathrm{e}}$ and $\pi$ were estimated directly from STACKS output and $A_{\mathrm{r}}$ was estimated using HP-RARE 1.0 (Kalinowski 2005). Importantly, estimates of $H_{\mathrm{o}}, H_{\mathrm{e}}$ and $\pi$ are relatively insensitive to sample size, especially when the number of loci used is large (Nei 1978); $A_{\mathrm{r}}$ uses a rarefaction approach to correct for variation in sample sizes.

We estimated effective population size $\left(N_{\mathrm{e}}\right)$ of island fox populations using the linkage disequilibrium (LD) method implemented in program NEESTIMATOR 2.01 (Do et al. 2014). This method is based on theory showing that the amount of linkage (i.e., gametic) disequilibrium at independent loci in randomly mating, isolated populations is purely a function of the magnitude of genetic drift and can therefore be used to estimate $N_{\mathrm{e}}$ (Hill 1981). The LD method provides a contemporary estimate of $N_{\mathrm{e}}$ in the previous generation, although it can also be affected by LD generated over several generations (Waples 2005). Because island foxes have overlapping generations, the LD method estimates the effective number of breeders $\left(N_{\mathrm{b}}\right)$ that produced the sampled cohort(s), which may or may not be the per-generation estimate of $N_{\mathrm{e}}$. However, the relationship between $N_{\mathrm{e}}$ and $N_{\mathrm{b}}$ for single-sample estimates of $N_{e}$ remains unclear (Waples 2010), so here, we refer to our estimates as $N_{\mathrm{e}}$.

As this method assumes that markers are selectively neutral, we estimated $N_{\mathrm{e}}$ using only presumably neutral loci not identified as high $F_{\mathrm{ST}}$ outliers (which may be under divergent selection). For the purposes of this analysis, we identified high $F_{\mathrm{ST}}$ outliers as those loci with the top $5 \%$ of global $F_{\mathrm{ST}}$ values (Hohenlohe et al. 2010a) and then removed these outlier loci before running NEESTIMATOR, leaving 4615 loci for analysis. This simple nonmodel-based approach for identifying high $F_{\mathrm{ST}}$ outlier loci may incorrectly identify some loci as outliers that in reality are not under divergent selection (i.e., false positives) (Bierne et al. 2013). Thus, this is a conservative approach because it errs on the side of removing too many loci.

We tested for evidence of population bottlenecks in each of the six island fox subspecies and the mainland grey fox species using the program BotTLENECK 1.2.02 (Cornuet \& Luikart 1996; Piry et al. 1999). This analysis is based on the loss of rare alleles predicted in recently bottlenecked populations, resulting in heterozygosity excess. As this method assumes that markers are selectively neutral, we only used nonoutlier loci, identified using the "top 5\% method" as explained above. We used the infinite alleles model (IAM) as the most appropriate evolutionary model for SNP loci. To test for significant heterozygosity excess compared to the level predicted under mutation-drift equilibrium, we used a one-tailed Wilcoxon signed rank test implemented in $\mathrm{R}$ v3.1.3. Stringent filters on minor allele frequency (MAF) 
could bias this analysis in favour of detecting bottlenecks because rare alleles are removed. Therefore, we carried out two sets of analyses, the first using all nonoutlier loci that met the standard MAF filter of $>0.1$, and the second using all nonoutlier loci that met a less stringent filter of MAF $>0.02$.

To test the second prediction that genetic differentiation between island fox populations and the mainland will be negatively correlated with the magnitude of genetic drift, we conducted linear regression analyses with pairwise estimates of $F_{\mathrm{ST}}$ between each island fox population vs. grey foxes as the response variable and $H_{\mathrm{o}}, H_{\mathrm{e}}, A_{\mathrm{r}}$ or $\pi$ as the predictor variable (in four separate regression analyses). This analysis assumes that within island genetic variation is a reasonable index of the magnitude of historical genetic drift, which should be a valid assumption, due to minimal gene flow among island fox populations and grey foxes after initial colonization of the islands (Hofman et al. 2015). Therefore, gene flow would not be expected to contribute significantly to within-island genetic variation.

Aim 3: test the contribution of divergent selection to genetic differentiation. Divergent selection could contribute to genetic differentiation of a subset of loci or genome-wide. In the early stages of adaptive divergence, selection is predicted to target specific loci underlying traits involved in local adaptation, causing a relatively small subset of loci to be identified as high $F_{\mathrm{ST}}$ outliers with higher genetic differentiation than background, neutral levels (Beaumont \& Nichols 1996; Beaumont \& Balding 2004; Hohenlohe et al. 2010a,b). If adaptive divergence proceeds to the point of causing reproductive isolation in the process of ecological speciation, "isolation-by-adaption" can result whereby genome-wide genetic differentiation is correlated with environmental differences among populations (Nosil et al. 2008). We tested both of these possible outcomes of divergent selection in island foxes.

First, we identified high $F_{\mathrm{ST}}$ outliers among island fox populations (without grey foxes) using three outlier tests: a nonmodel-based method (loci with the highest $5 \%$ of $F_{\mathrm{ST}}$ values, described above); a maximum likelihood test implemented in FDisT2 (Beaumont \& Nichols 1996; Beaumont \& Balding 2004); and a Bayesian approach implemented in BAYESFST (Beaumont \& Balding 2004). Both of these methods have been shown to be relatively robust to deviations from assumed population structure (Beaumont \& Balding 2004). FDisT2 was run assuming either a simple island model or a hierarchical island model with islands nested in separate northern (SMI, SRI, SCI) and southern (SCA, SCL, SNI) groups. To standardize the false positive rate between FDIST2 and BAYESFST, we set the critical $P$-value to 0.01 for FDIST2 to compare with the Bayesian $10 \%$ level, as recommended by Beaumont \& Balding (2004). With a critical $P$-value of $0.01,1 \%$ of loci should be identified as high $F_{\mathrm{ST}}$ outliers by chance. Thus, following previous studies (Beaumont \& Balding 2004; Willing et al. 2010), if $>1 \%$ of loci were identified as high $F_{\mathrm{ST}}$ outliers, we interpreted this as evidence of true divergent selection and adaptive divergence. We also corrected for type I errors from multiple testing in FDIST2 using a false discovery rate (FDR) correction (Benjamini \& Hochberg 1995). BAYESFST already addresses the problem of multiple testing through the prior distribution of the regression parameter for the locus effect (Beaumont \& Balding 2004). We then ran a Gene Ontology (GO) term enrichment analysis (Mi et al. 2013) for those high $F_{\mathrm{ST}}$ outliers that blasted to genes in the dog (Canis lupus familiaris) genome (canFam3.1; Hoeppner et al. 2014). The GO analysis tested for overrepresentation of genes associated with specific biological processes relative to the full set of dog genes.

To complement our high $F_{\mathrm{ST}}$ outlier tests, we tested for loci associated with environmental variation with BAYESCENV (Villemereuil \& Gaggiotti 2015). This method considers a model incorporating environmental data from each collection site, and compares that to both the null $F$-model and standard $\alpha$-model to identify $F_{\mathrm{ST}}$ outlier loci that show variation associated with environmental differentiation. We considered five environmental variables hypothesized to be related to adaptive divergence among island fox populations: mean annual temperature and precipitation (Weigelt et al. 2013) and three dietary variables that reflect differences in prey availability among islands (proportion of insects, fruit or mice in the diet; Cypher et al. 2014).

BAYESCENV was run for each of the environmental variables with the parameter settings of: $g$ (upper bound) $=10 ; \alpha$ (mean prior) $=-1.0 ; P=0.50$; and $\pi=0.10$. After 20 pilot runs of 2000 iterations each and a burn-in of 50000 iterations, 5000 MCMC samples were taken with 10 steps between each sample. Diagnostics of the $\log$ likelihoods and $F_{\mathrm{ST}}$ values for the 5000 sampled iterations were checked using the 'coda' package in $\mathrm{R}$ to confirm convergence and sample sizes of at least 2500 .

Second, we tested for relationships between genomewide genetic differentiation and environmental differences among populations using multiple regression on distance matrices (MRDM; Legendre et al. 1994; Balkenhol et al. 2009). MRDM regresses multiple predictor matrices against a response matrix of genetic distances, and uses permutation to assess statistical significance. The MRM function in the R package 'ecodist' (Goslee \& Urban 2007) was run with 1000 permutations using the genetic distance matrices $\left(F_{\mathrm{ST}}\right.$ or Jost's $\left.D\right)$ as the response variable. Each of three matrices representing climatic differences among the islands (mean 
temperature and precipitation; Weigelt et al. 2013) and dietary differences (Horn's similarity index; Cypher et al. 2014), along with the geographic distance matrix were used as the predictor variables. Prior to running MRDM, we used variance inflation factors (VIF) to assess multicollinearity among predictor variables. Geographic distance and temperature were highly correlated $(>80 \%$ ) but had VIF values $<4$; thus, both factors were retained for the subsequent analyses. To obtain a best-reduced model, stepwise regression with both forward and backward selection was implemented with the 'step' function in R. A full MRDM model that included all predictor variables was then run, as well as a model that considered geographic distance alone.

Aim 4: characterize population divergence at neutral vs. adaptive loci. Lastly, we used the results of the above outlier tests to partition our SNP data set into nonoutlier (presumably neutral) and high $F_{\mathrm{ST}}$ outlier (presumable adaptive) loci for examining patterns of genetic divergence and similarity using PCA and Neighbournet trees (Funk et al. 2012). In addition, we used the previously described nonmodel-based method of identifying outliers, in which loci with the highest $5 \%$ of $F_{\mathrm{ST}}$ values were designated as outliers, as a third way to partition our data set.

\section{Results}

\section{$R A D$ sequencing and genotyping}

After filtering for read quality and presence of a correct barcode and SbfI recognition site, a total of 93314044 "clean" read pairs were generated across the eight individuals included in the paired-end Illumina HiSeq lane. Of these, 69\% were identified as PCR duplicates and were removed, leaving 29357186 read pairs from which we assembled a total of 126264 unique consensus RAD contigs.

Single-end sequencing yielded 494418159 clean sequence reads across 192 individuals. These were added to 55262507 clean forward reads from the eight individuals included in the paired-end sequencing lane for a total of 549680666 clean reads from 200 individuals that were aligned to the above 126264 RAD contigs. After all quality filters, a total of 4858 variable SNP loci were available for analysis when the grey fox outgroup was included and 5293 SNPs were available without grey foxes (Table 2). Mean coverage per locus (averaged across individuals) ranged from 5-40 (median $=20$; Fig. S1, Supporting information) and the number of loci per individual (for the data set including grey foxes) ranged from 2381 to 4854 (median $=4419$ [ $=91 \%$ of all variable SNPs]; Fig. S2, Supporting information).

\section{Aim 1: characterize population structure}

We found exceptionally high genetic differentiation among island fox populations. Pairwise $F_{\mathrm{ST}}$ values between most islands were extremely high, ranging from 0.463 to 0.963 (median $=0.749$ ), and all values were statistically significant $(P<0.00001$; Table 3$) . F_{\mathrm{ST}}$ values were insensitive to the threshold used for the allowed level of missing genotypes, as revealed by a high correlation between pairwise $F_{\mathrm{ST}}$ values calculated using our standard threshold of $<50 \%$ missing genotypes vs. a more stringent threshold of $<20 \%$ missing genotypes $(r=0.999, P<0.00001)$. Pairwise Jost's $D$ values were also significantly correlated with pairwise $F_{\mathrm{ST}}$ values $(r=0.711, P=0.0003)$, although SNI was more similar to SCL with Jost's $D$ than with $F_{\mathrm{ST}}$ (Table 3).

The best-supported value of $K$ in our STRUCTURE analysis was $K=7$ based on mean $\operatorname{LnP}(K)$ and $K=2$ based on the $\Delta K$ method. However, $K=2$ was clearly an underestimate based on our $F_{\mathrm{ST}}$, Jost's $D$, PCA, and Neighbour-net results. Interestingly, although $K=7$ was best-supported based on mean $\operatorname{LnP}(K)$, no individuals had any measurable portion (to the thousandths place) of their genome assigned to the seventh cluster, meaning $K=6$ effectively had the highest support. With $K=7$, individuals were generally assigned to a single island (or to the mainland, in the case of grey foxes; Fig. 2). However, approximately $73 \%$ of the genomes of individuals from SRI were assigned to SMI and approximately $27 \%$ to SCI, indicating SRI has an intermediate genetic relationship to SMI and SCI. Several individuals on SCA also had a small proportion of their genomes (mean $=1.3 \%)$ assigned to SCI.

As expected, all island foxes grouped by island in the PCA (Fig. 3) and Neighbour-net tree (Fig. 4). Removal of grey foxes did not change this result (Figs $3 b$ and $4 b)$. Island fox populations grouped geographically,

Table 2 Counts of SNP loci after each step of filtering with or without grey foxes included

\begin{tabular}{|c|c|c|c|c|}
\hline \multirow[b]{2}{*}{ Filtering step } & \multicolumn{2}{|c|}{$\begin{array}{l}\text { With grey } \\
\text { foxes included }\end{array}$} & \multicolumn{2}{|c|}{$\begin{array}{l}\text { Without grey } \\
\text { foxes included }\end{array}$} \\
\hline & Count & $\begin{array}{l}\% \text { of } \\
\text { total }\end{array}$ & Count & $\begin{array}{l}\% \text { of } \\
\text { total }\end{array}$ \\
\hline (1) Total contigs & 126264 & 100.0 & 126264 & 100.0 \\
\hline $\begin{array}{l}\text { (2) SNPs w/genotypes for } \\
\geq 50 \% \text { individuals }\end{array}$ & 50135 & 39.7 & 20153 & 16.0 \\
\hline (3) $1 \mathrm{SNP}$ per contig & 30719 & 24.3 & 15291 & 12.1 \\
\hline $\begin{array}{l}\text { (4) Minor allele frequency } \\
\text { (MAF) } \geq 0.10\end{array}$ & 4997 & 4.0 & 5404 & 4.3 \\
\hline $\begin{array}{l}\text { (5) Coverage } \leq \text { mean } \\
\text { coverage }+2 \mathrm{SD}\end{array}$ & 4858 & 3.8 & 5293 & 4.2 \\
\hline
\end{tabular}


with two broad clusters representing northern island (SMI, SRI, and SCI) and southern island (SCA, SCL, SNI) populations.

\section{Aim 2: test the contribution of genetic drift to genetic differentiation}

Island fox populations had low within-population genetic variation compared to mainland grey foxes (Table 4). This pattern was evident for all four measures of genetic variation estimated (observed heterozygosity $\left[H_{\mathrm{o}}\right]$, expected heterozygosity $\left[H_{\mathrm{e}}\right]$, allelic richness $\left[A_{\mathrm{r}}\right]$, nucleotide diversity $[\pi]$ ), but was most pronounced for $\pi$, which is based on invariant sites as well as SNPs (whereas the other three measures are only based on

Table 3 Pairwise $F_{\mathrm{ST}}$ estimates below diagonal and Jost's $D$ estimates above diagonal between all pairs of island fox and grey fox populations

\begin{tabular}{llllllll}
\hline & $\begin{array}{c}\text { Grey } \\
\text { foxes }\end{array}$ & SMI & SRI & SCI & SCA & SCL & SNI \\
\hline $\begin{array}{l}\text { Grey } \\
\text { foxes }\end{array}$ & - & 0.376 & 0.345 & 0.346 & 0.282 & 0.357 & 0.384 \\
SMI & 0.664 & - & 0.136 & 0.325 & 0.457 & 0.460 & 0.603 \\
SRI & 0.589 & 0.515 & - & 0.199 & 0.368 & 0.392 & 0.547 \\
SCI & 0.623 & 0.773 & 0.584 & - & 0.291 & 0.362 & 0.527 \\
SCA & 0.462 & 0.676 & 0.596 & 0.558 & - & 0.204 & 0.237 \\
SCL & 0.629 & 0.884 & 0.749 & 0.778 & 0.463 & - & 0.239 \\
SNI & 0.814 & 0.963 & 0.902 & 0.919 & 0.646 & 0.914 & - \\
\hline
\end{tabular}

Pairwise $F_{\mathrm{ST}}$ and Jost's $D$ estimates were calculated from 4858 SNP loci using ARLEQUIN 3.5 (Excoffier et al. 2005) and GENALEX 6.5 (Peakall \& Smouse 2006, 2012), respectively. All pairwise $F_{\mathrm{ST}}$ estimates were statistically significant. See Fig. 1 for full names of islands abbreviated here.
SNPs). Effective population sizes $\left(N_{\mathrm{e}}\right)$ estimated using NEESTIMATOR were also generally small on islands, ranging from 2.1-89.7 (median $=19.4$ ), relative to an $N_{e}$ of 109.2 for our mainland grey fox population (Table 4). Finally, вотTLENECK found overwhelming evidence for historical bottlenecks in all populations (island foxes and grey foxes), regardless of whether a MAF filter of $>0.10$ or $>0.02$ was used (Wilcoxon signed rank test, $P<0.000001$ ).

Also as predicted, pairwise $F_{\mathrm{ST}}$ values between grey foxes vs. island fox populations were significantly predicted by within-island genetic variation (Fig. $5 ; H_{\mathrm{o}}$ : $F_{1,4}=28.35, P=0.006 ; H_{\mathrm{e}}: F_{1,4}=28.44, P=0.006 ; A_{\mathrm{r}}:$ $\left.F_{1,4}=29.56, P=0.006 ; \pi: F_{1,4}=42.45, P=0.003\right)$. For example, grey foxes were most genetically similar to island foxes on SCA, which had the highest withinpopulation genetic variation, and were most genetically divergent from island foxes on SNI, which had the lowest genetic variation.

\section{Aim 3: test the contribution of divergent selection to genetic differentiation}

Mean $F_{\mathrm{ST}}$ among all populations was 0.726 , but many loci had $F_{\mathrm{ST}}$ values of one or close to one, suggesting they may be high $F_{\mathrm{ST}}$ outliers (Fig. 6). We used three different tests to identify high $F_{\mathrm{ST}}$ outlier loci with a signature of divergent selection and adaptive divergence among the six island fox populations: a nonmodel-based method (loci with the highest $5 \%$ of $F_{\mathrm{ST}}$ values); a likelihood model-based method (implemented in FDIST2); and a Bayesian model-based method (implemented in BAYESFST). As we set the critical $P$ value to 0.01 for the two model-based approaches, we expected 53 loci ( $1 \%$ of the total 5293 loci) to be identi-

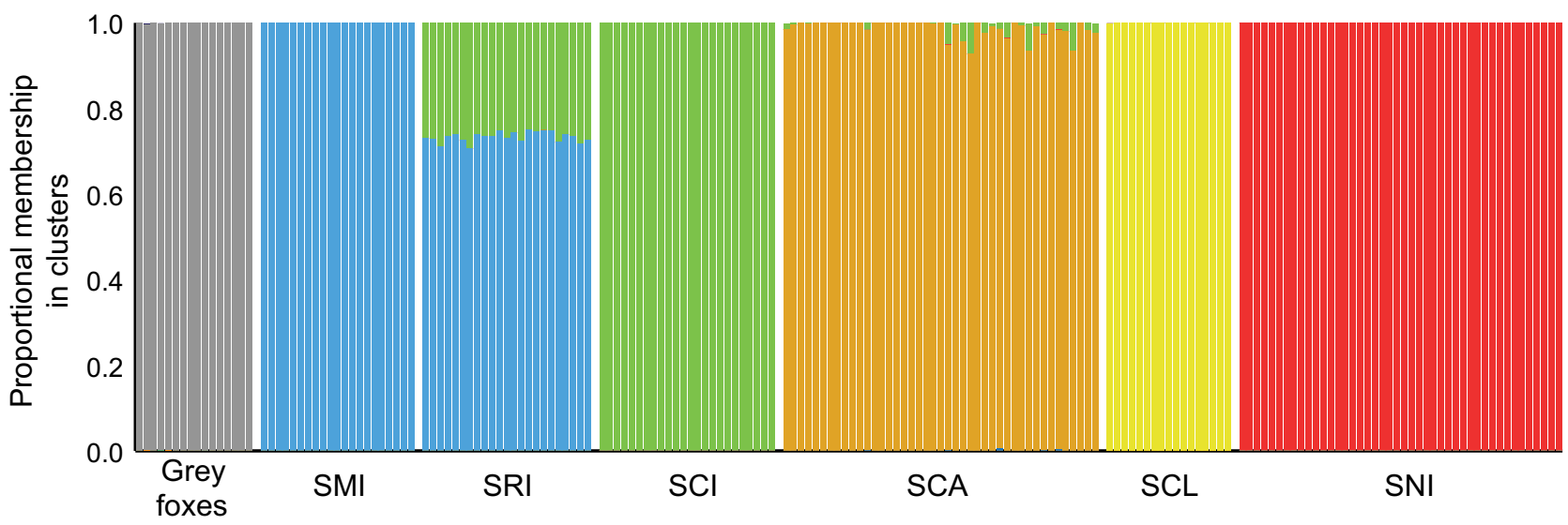

Fig. 2 Results from Bayesian individual clustering with STRUCTURE for $K=7$. Each colour corresponds to a distinct genetic cluster and each bar corresponds to the proportion of an individual's genotype assigned to each cluster. Note that although $K=7$ was the bestsupported number of $K$, no individuals had any measurable portion (to the thousandths place) of their genome assigned to the seventh cluster, meaning $K=6$ effectively had the highest support. 


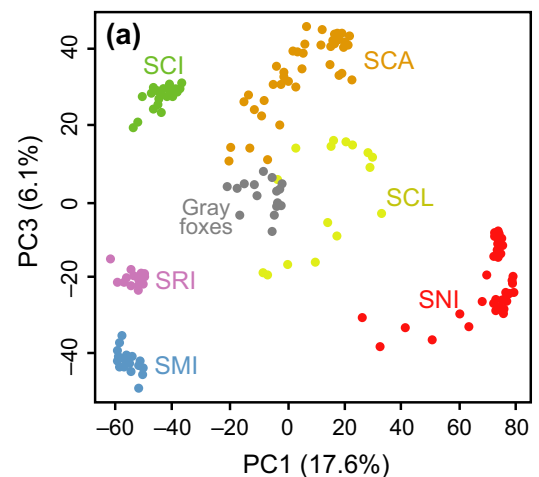

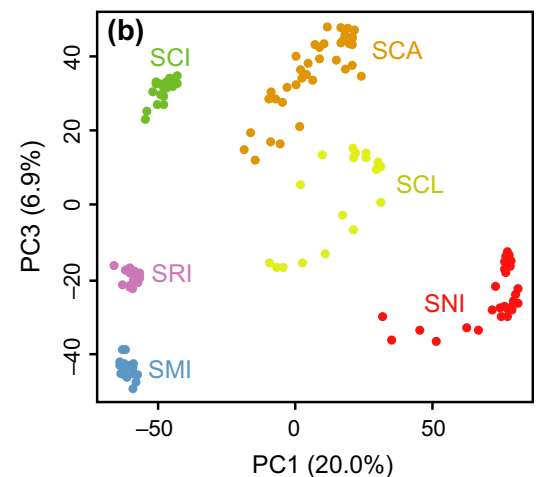

Fig. 3 Principal component analysis (PCA) to characterize genetic differentiation among island fox populations using SNP loci with (a) or without (b) the grey fox outgroup. As PC2 primarily reflected the amount of missing data, we used PC1 and PC3 to visualize genetic divergence among individuals. Colours and abbreviations correspond to different islands as shown in Fig. 1. fied as significant high $F_{\mathrm{ST}}$ outliers by chance. However, $351(6.6 \%)$ and $188(3.6 \%)$ loci were actually identified as high $F_{\mathrm{ST}}$ outliers by FDIST2 and BAYESFST, respectively, suggesting that many of these loci (or linked loci) are under divergent selection. Moreover, the FDIST2 outlier test assuming a hierarchical island model (rather than the simple island model assumed above) still identified $325(6.1 \%)$ loci as high $F_{\mathrm{ST}}$ outliers, indicating the results were insensitive to the model. Similarly, 297 (5.6\%) loci were still identified by FDist2 as high $F_{\mathrm{ST}}$ outliers even after the false discovery rate (FDR) correction.

In addition, 437 out of 439 loci identified as high $F_{\mathrm{ST}}$ outliers by at least one of the above three tests blasted to the dog genome (median E-value $=0$; range $=0$ $\left.1.41 \times 10^{-24}\right)$ and 195 out of these 437 loci $(44.6 \%)$ blasted to genes (Table S1, Supporting information), indicating many high $F_{\mathrm{ST}}$ outliers are functional. Gene Ontology (GO) term enrichment analysis of the outliers that blasted to dog genes uncovered three categories of gene function that were statistically overrepresented relative to the full set of dog genes. These included genes involved in regulation of catalytic activity (Bonferronicorrected $P=0.044)$, cellular protein modification $(P=0.046)$, and regulation of molecular function $(P=0.050)$. However, no loci were significantly associated with the climatic or diet variables tested in BAYESCENV $(P>0.05)$.

We did not find any evidence of an effect of environmental differences among islands on genome-wide genetic distance. Matrix regression results (Table 5) using geometric distance as a predictor were not significant for either genetic distance measure $\left(F_{\mathrm{ST}}\right.$ : $F_{1,13}=0.236, r^{2}=0.018, P=0.60$; Jost's $D: F_{1,13}=0.021$, $\left.r^{2}=0.002, P=0.90\right)$, nor was the full model that also incorporated all three habitat distance matrices as predictors $\left(F_{\mathrm{ST}}: F_{5,9}=0.406, r^{2}=0.140, P=0.89\right.$; Jost's $D$ : $\left.F_{5,9}=0.285, r^{2}=0.102, P=0.84\right)$. In addition, model selection based on AIC did not identify any of the habitat distance matrices as significant predictors. (a)

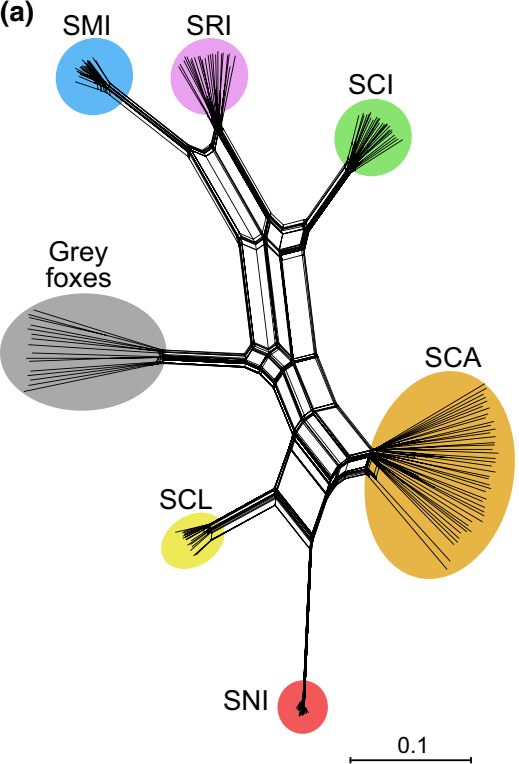

(b)
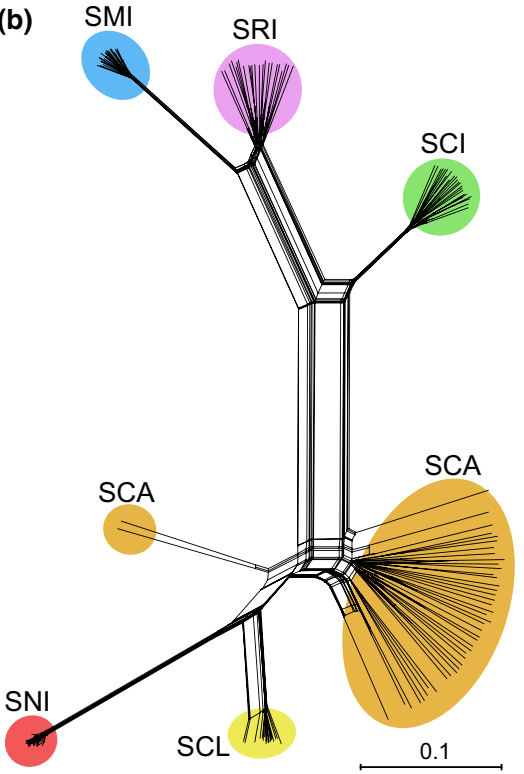

Fig. 4 Neighbour-net tree to characterize genetic differentiation among island fox populations using SNP loci with (a) or without (b) the grey fox outgroup. Colours and abbreviations correspond to different islands as shown in Fig. 1. 
Aim 4: characterize population divergence at neutral vs. adaptive loci

Patterns of population divergence based on high $F_{\mathrm{ST}}$ outlier (presumably adaptive) vs. nonoutlier (presumably neutral) loci differed in two different ways. The main consistent difference as seen with both PCA

Table 4 Observed heterozygosity $\left(H_{\mathrm{o}}\right)$, expected heterozygosity $\left(H_{\mathrm{e}}\right)$, allelic richness $\left(A_{\mathrm{r}}\right)$, nucleotide diversity $(\pi)$, and effective population size estimates $\left(N_{\mathrm{e}}\right.$, with $95 \%$ confidence intervals) for mainland grey foxes and each island fox population

\begin{tabular}{llllll}
\hline & & & & & \multicolumn{2}{l}{$\begin{array}{l}N_{\mathrm{e}}(95 \% \\
\text { confidence } \\
\text { intervals })\end{array}$} \\
Site & $H_{\mathrm{o}}$ & $H_{\mathrm{e}}$ & $A_{\mathrm{r}}$ & $\pi$ & \\
\hline $\begin{array}{c}\text { Grey } \\
\text { foxes }\end{array}$ & 0.238 & 0.261 & 1.73 & 0.00296 & $109.2(105.2-113.6)$ \\
SMI & 0.060 & 0.059 & 1.16 & 0.00027 & $13.7(13.2-14.1)$ \\
SRI & 0.147 & 0.148 & 1.39 & 0.00054 & $13.6(13.5-13.7)$ \\
SCI & 0.114 & 0.112 & 1.30 & 0.00045 & $25.1(24.6-25.5)$ \\
SCA & 0.231 & 0.251 & 1.65 & 0.00082 & $47.0(46.7-47.4)$ \\
SCL & 0.065 & 0.064 & 1.17 & 0.00033 & $89.7(77.1-107.0)$ \\
SNI & 0.016 & 0.011 & 1.03 & 0.00012 & $2.1(2.0-2.2)$ \\
\hline
\end{tabular}

(Fig. 7; Figs S3 and S4, Supporting information) and Neighbour-net trees (Fig. 8; Figs S5 and S6, Supporting information) is that SCI is more similar to SCA when using outliers vs. nonoutliers. Moreover, SNI is very divergent from all other populations based on outlier loci identified using the top 5\% method and FDist2, but more similar to SCL based on outlier loci identified using BAYESFST.

\section{Discussion}

Our analysis of over 5000 SNPs revealed that genetic drift is the dominant evolutionary force driving genetic differentiation among island fox populations. Three lines of evidence support this conclusion. First, genetic variation, particularly nucleotide diversity $(\pi)$, was much lower in island fox populations than in their sister species, the grey fox, or other species with published data on $\pi$. Second, most island fox populations have low (in some cases, extremely low) effective population sizes $\left(N_{\mathrm{e}}\right)$, and all have genetic signatures of historical bottlenecks. Third, the significant negative relationship between pairwise $F_{\mathrm{ST}}$ (between each island fox population and mainland grey foxes) and measures of within
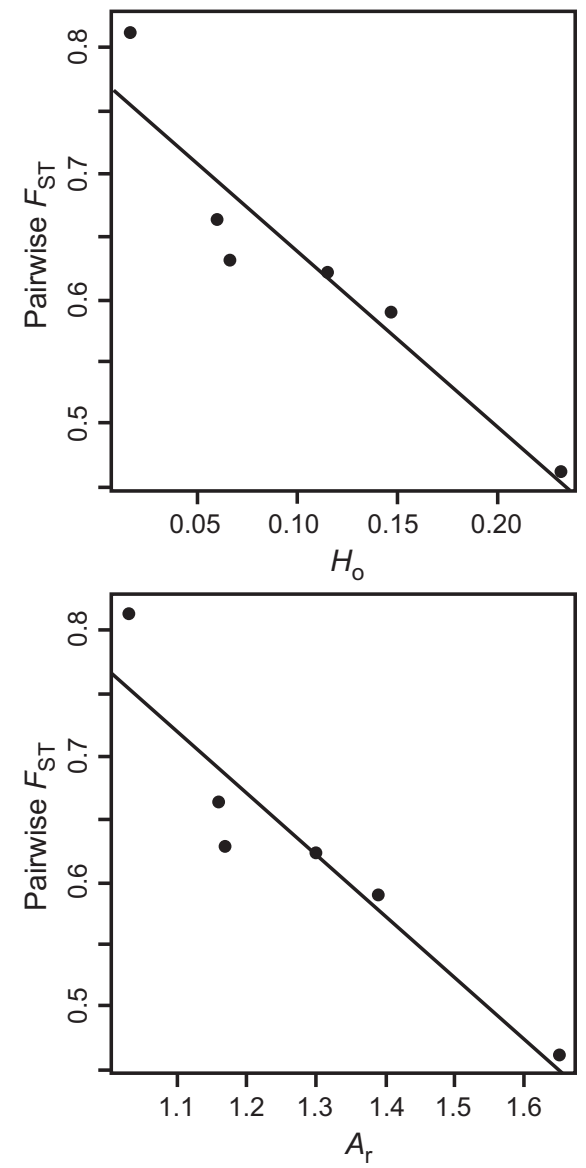
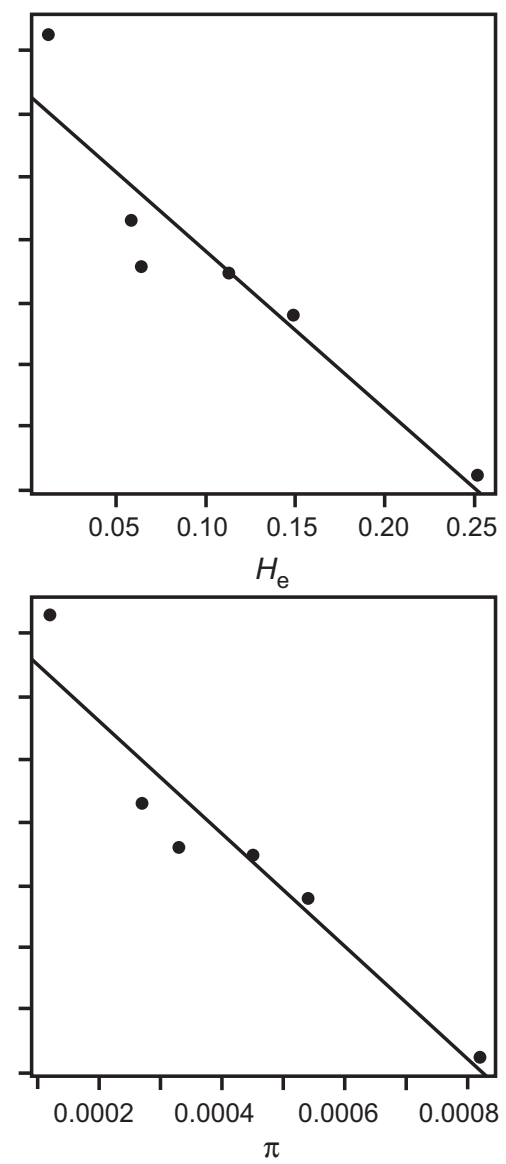

Fig. 5 Scatterplots of pairwise $F_{\mathrm{ST}}$ values between grey foxes and each island fox population vs. different measures of within population genetic variation $\left(H_{\mathrm{o}}\right.$ observed heterozygosity; $H_{\mathrm{e}}$, expected heterozygosity; $A_{\mathrm{r}}$, allelic richness; $\pi$, nucleotide diversity). All four relationships were statistically significant $(P<0.05$; indicated by solid black regression lines). 
population genetic variation suggests that the strength of genetic drift determines the degree of divergence.

Nonetheless, we also uncovered evidence for adaptive divergence among island fox populations based on high $F_{\mathrm{ST}}$ outlier tests, indicating that divergent selection may have contributed to divergence despite strong genetic drift (McKay et al. 2001). No loci were associated with variation in climate or diet. However, patterns of population similarity at high $F_{\mathrm{ST}}$ outlier loci mirrored patterns of morphological similarity (discussed below), suggesting genetically based, adaptive differences exist among populations, supporting subspecies designation.

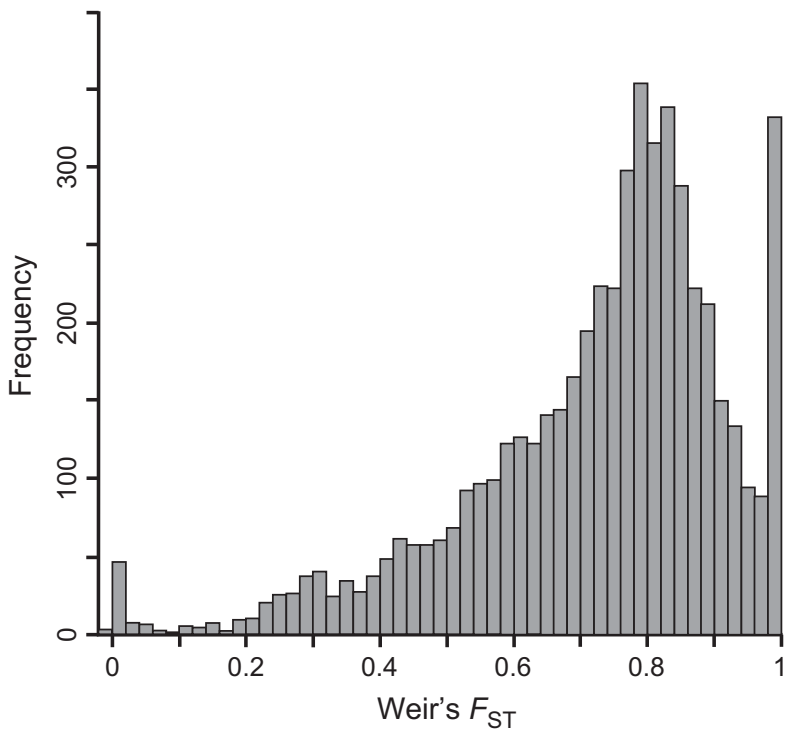

Fig. 6 Histogram of Weir's $F_{\mathrm{ST}}$ values among all island fox populations at $5293 \mathrm{SNP}$ loci.
Alone, the finding of adaptive divergence among island fox populations suggests that they should continue to be managed separately. However, extremely low genetic variation and $N_{e}$ found on some populations, particularly SNI, indicate that they are vulnerable to negative inbreeding effects and loss of genetic variation. These populations might therefore benefit from genetic rescue using source individuals from another island. These opposing management options-managing islands separately to maintain adaptive differences vs. supplementing small, declining populations with individuals from another island to boost fitness through genetic rescue - create a management conundrum. We argue that this uncertainty could best be resolved by research to determine the severity of inbreeding depression, if any, and the potential benefits/costs of genetic rescue. Below, we discuss these and other results in more detail.

\section{High genetic differentiation}

Our finding of high genetic differentiation among island fox populations using a large number of genome-wide markers is in agreement with the results of previous studies that used traditional molecular markers, including allozymes, minisatellites, mtDNA and microsatellites (Wayne et al. 1991; Goldstein et al. 1999). We found that in some cases, genetic differentiation was exceptionally high, particularly between SNI and other island populations, with pairwise $F_{\mathrm{ST}}$ values ranging from 0.646 to 0.963 . Importantly, the measure of genetic differentiation we used did not affect our conclusion that island fox populations were highly divergent from each other. Genetic differentiation measured using $F_{\mathrm{ST}}$ and

Table 5 Results of multiple regression on distance matrices (MRDM)

\begin{tabular}{|c|c|c|c|c|c|c|c|}
\hline Genetic distance & MRM model & & Coef & $P$-value & $r^{2}$ & $F$ & $P$-value \\
\hline \multirow[t]{7}{*}{$F_{\mathrm{ST}}$} & \multirow[t]{2}{*}{$\mathrm{p} F_{\mathrm{ST}} \sim \mathrm{Geo}$} & Int & 0.547 & 0.70 & \multirow[t]{2}{*}{0.018} & \multirow[t]{2}{*}{0.236} & \multirow[t]{2}{*}{0.60} \\
\hline & & Geo & 0.000 & 0.60 & & & \\
\hline & \multirow[t]{5}{*}{ Full model } & Int & 0.447 & 0.77 & \multirow[t]{5}{*}{0.140} & \multirow[t]{5}{*}{0.406} & \multirow[t]{5}{*}{0.89} \\
\hline & & Geo & 0.001 & 0.69 & & & \\
\hline & & Diet & 0.322 & 0.59 & & & \\
\hline & & Temp & -0.112 & 0.66 & & & \\
\hline & & Precip & 0.000 & 0.90 & & & \\
\hline \multirow[t]{7}{*}{ Jost's $D$} & \multirow[t]{2}{*}{$\mathrm{p} D \sim \mathrm{Geo}$} & Int & 0.362 & 0.65 & \multirow[t]{2}{*}{0.002} & \multirow[t]{2}{*}{0.021} & \multirow[t]{2}{*}{0.90} \\
\hline & & Geo & 0.000 & 0.90 & & & \\
\hline & \multirow[t]{5}{*}{ Full model } & Int & 0.330 & 0.63 & \multirow[t]{5}{*}{0.102} & \multirow[t]{5}{*}{0.285} & \multirow[t]{5}{*}{0.84} \\
\hline & & Geo & 0.000 & 0.74 & & & \\
\hline & & Diet & 0.210 & 0.56 & & & \\
\hline & & Temp & -0.053 & 0.70 & & & \\
\hline & & Precip & 0.000 & 0.49 & & & \\
\hline
\end{tabular}

Int $=y$-intercept Geo = geographic distance; Diet $=$ Horn's similarity index for diet; Temp = difference in mean annual temperature; Precip $=$ difference in mean annual precipitation. 

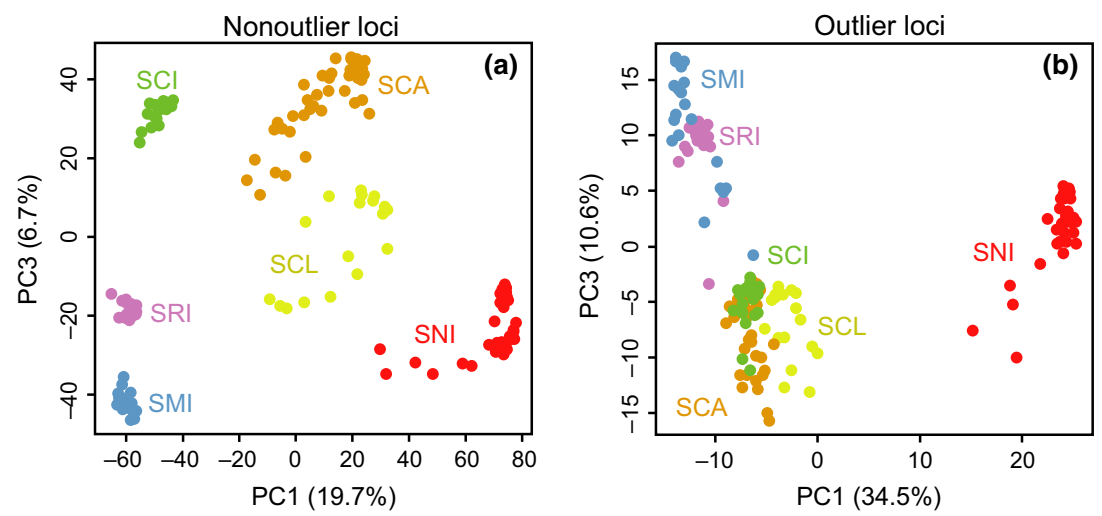

Fig. 7 Principle component analysis (PCA) to characterize genetic differentiation among island fox populations using high $F_{\mathrm{ST}}$ outlier SNPs or nonoutliers. (a) PCA based on 5028 presumably neutral SNPs not identified as high $F_{\mathrm{ST}}$ outliers or (b) 265 presumably adaptive SNPs identified as high $F_{\mathrm{ST}}$ outliers. Here, outlier loci were identified as the highest $5 \%$ of $F_{\mathrm{ST}}$ values. As PC2 primarily reflected the amount of missing data, we used PC1 and PC3 to visualize genetic divergence among individuals. Colours and abbreviations correspond to different islands as shown in Fig. 1. See Figs S3 and S4 (Supporting information) for PCA using four different methods for identifying outlier loci (highest $5 \%$ of $F_{\mathrm{ST}}$ values, FDIST2, FDisT2 with the false discovery rate correction, or BAYESFST) with (Fig. S3, Supporting information) or without (Fig. S4, Supporting information) grey foxes.

(a)

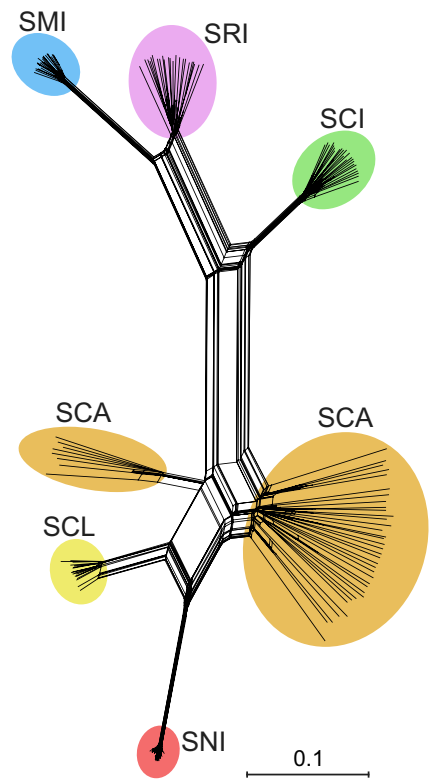

(b)

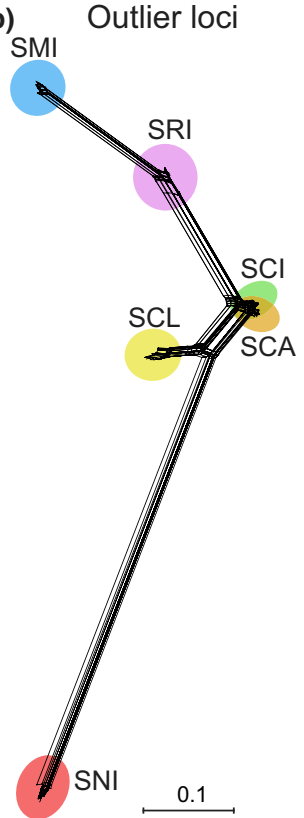

Fig. 8 Neighbour-net trees to characterize genetic differentiation among island fox populations using high $F_{\mathrm{ST}}$ outlier SNPs or nonoutliers. (a) Neighbour-net trees based on 5028 presumably neutral SNPs not identified as high $F_{\mathrm{ST}}$ outliers or (b) 265 presumably adaptive SNPs identified as high $F_{\mathrm{ST}}$ outliers. Here, outlier loci were identified as the highest $5 \%$ of $F_{\mathrm{ST}}$ values. Colours and abbreviations correspond to different islands as shown in Fig. 1. See Figs S5 and S6 (Supporting information) for Neighbour-net trees using four different methods for identifying outlier loci (highest $5 \%$ of $F_{\mathrm{ST}}$ values, FDIST2, FDisT2 with the false discovery rate correction, or BAYESFST) with (Fig. S5, Supporting information) or without (Fig. S6, Supporting information) grey foxes.

Jost's $D$ were highly concordant $(r=0.711, P<0.00001)$. The main exception to this concordance was that SNI was more similar to SCL using Jost's $D$ than $F_{\mathrm{ST}}$. Although some have recently argued that some measures of genetic differentiation are superior to others (Verity \& Nichols 2014), our results were insensitive to the measure used.

As expected based on high $F_{\mathrm{ST}}$ values and previous work, Structure identified each island as a distinct genetic cluster, with the exception of SRI, in which each individual had an average of $73 \%$ of its genome assigned to SMI and $27 \%$ assigned to SCI, indicating a genetic composition intermediate to these two populations (Fig. 2). The intermediate position of SRI between SMI and SCI was also apparent in the PCA (Fig. 3) and Neighbour-net trees (Fig. 4). Interestingly, a small proportion of some individuals genomes on SCA were assigned to $\mathrm{SCI}$, which is in agreement with the finding of a SCI mtDNA haplotype in the SCA population, suggesting a recent human movement of island foxes from SCI to SCA (Hofman et al. 2015). This result is interesting in light of the potential use of genetic rescue in island foxes (see "Conservation implications" below); introduction of these individuals did not have any detectable, long-term negative consequences for the SCA population. SCA maintained its genetic distinctness despite anthropogenically-mediated gene flow.

The PCA and Neighbour-net analyses showed the same overall pattern of genetic relationships among island fox populations (Figs 3 and 4). Both clustered individuals by their island of origin, as expected based on high $F_{\mathrm{ST}}$ and Jost's $D$ values among populations, and both grouped the northern islands (SMI, SRI, and 
SCI) together and the southern islands (SCA, SCL and $\mathrm{SNI})$ together. These results, once again, are in general agreement with patterns uncovered from previous genetic studies (Wayne et al. 1991; Goldstein et al. 1999), suggesting that when genetic structure is pronounced, as in the case of island foxes, relatively small numbers of traditional markers may be sufficient for inferring population structure.

\section{Contribution of genetic drift to genetic differentiation}

We found overwhelming evidence for strong genetic drift in island fox populations. Genetic variation was much lower in island fox populations than in mainland grey foxes based on all four measures of genetic variation examined. In particular, nucleotide diversity $(\pi)$, which is based on invariant sites in addition to SNPs (and therefore more comparable among populations and species), was 3.6-24.7 times higher in grey foxes than island fox populations. Similarly, $\pi$ was approximately an order of magnitude higher in two bumble bee species (mean $\pi=0.0025-0.0041$ for Bombus impatiens and 0.0027-0.0042 for B. pensylvanicus; Lozier 2014), sticklebacks (0.00203-0.00268 in Gasterosteus aculeatus; Hohenlohe et al. 2010a), and endangered European eels (0.00529 for Anguilla anguilla; Pujolar et al. 2013), indicating island foxes are among the most genetically depauperate populations of sexually reproducing animals analysed with SNPs to date.

Effective population sizes $\left(N_{\mathrm{e}}\right)$ were small in five of six island fox populations analysed (SMI, SRI, SCI, SCA and SNI), which had effective population sizes ranging from 2.1 to 47.0. In contrast, $N_{\mathrm{e}}$ was significantly higher (89.7) in the one population, SCL, which has not experienced any recent documented bottlenecks. These $N_{\mathrm{e}}$ estimates, which reflect $N_{\mathrm{e}}$ from the last one to several generations, generally mirror the severity of known bottlenecks (compare known bottlenecks in Table 1 to $N_{e}$ estimates in Table 4). The $N_{\mathrm{e}}$ estimate of 2.1 from SNI is the lowest such value for any population of a sexually reproducing animal species of which we are aware.

We detected a genetic signal of population bottlenecks in all island fox populations, regardless of the minor allele frequency filter used. We were somewhat surprised by the discovery of a bottleneck in grey foxes on the mainland. However, in retrospect, this could reflect declines in this population, which is negatively affected by urbanization in southern California (Ordeñana et al. 2010).

Finally, the statistically significant negative relationship we found between pairwise $F_{\mathrm{ST}}$ (between each island fox population and the mainland grey fox population) and all measures of genetic variation strongly suggests that historical genetic drift has caused most variation in genetic differentiation among island fox populations. This same analysis has previously proven effective to test the effects of genetic drift and bottlenecks on population divergence (Jordan \& Snell 2008; Whiteley et al. 2010).

\section{Contribution of divergent selection to genetic differentiation}

Although the multiple regression on distance matrices (MRDM) analysis failed to find evidence for a genomewide association between genetic divergence and environmental factors (temperature, precipitation and diet), likelihood (FDisT2) and Bayesian (BAYESFST) outlier tests found evidence for high $F_{\mathrm{ST}}$ outlier loci that may be under divergent selection and involved in adaptive divergence. Many of these loci, as well as outliers identified using a nonmodel based approach (loci with the top $5 \%$ of $F_{\mathrm{ST}}$ values), blasted to genes in the dog genome, which were enriched for genes involved in regulation of catalytic activity, cellular protein modification and regulation of molecular function. However, no loci were associated with variation in the climatic or diet indices we used, suggesting that the high $F_{\mathrm{ST}}$ outlier loci identified must be involved in adaptation to other environmental factors.

Several recent studies have warned about the limitations of $F_{\mathrm{ST}}$ outlier tests for identifying loci under divergent selection, indicating that the results of these tests should be interpreted carefully. Other explanations for high $F_{\mathrm{ST}}$ outliers besides divergent selection include neutral factors, such as demographics (Lotterhos \& Whitlock 2014), recombination rate heterogeneity (Roesti et al. 2012), or background selection within populations (Cruickshank \& Hahn 2014). In addition, the assumptions of model-based outlier tests are rarely completely upheld. For example, like many outlier tests, FDIST2 and BAYESFST assume an island model in which migration is equally liked among all populations, an assumption that may not hold for island fox populations due to erratic and rare dispersal events among populations (for example, the human-mediated dispersal from SCI to SCA described above). Moreover, as these populations have become more and more divergent over time, even neutral loci may drift to fixation by chance, resulting in $F_{\mathrm{ST}}$ values equal to one. Nonetheless, the sensitivity of FDIST2, BAYESFST and other model-based outlier tests to their assumptions is poorly understood, so the high $F_{\mathrm{ST}}$ outliers identified may still be valid. This conclusion is supported by concordance between patterns of population similarity based on high $F_{\mathrm{ST}}$ outlier loci and patterns based on morphometric traits, discussed next. 
Population divergence at presumably neutral vs. adaptive loci

Overall, patterns of population divergence and similarity based on high $F_{\mathrm{ST}}$ outlier (presumably adaptive) vs. nonoutlier (presumably neutral) loci were similar, as seen in both PCA plots and Neighbour-net trees (Figs 7 and 8), but there were some notable exceptions. The principal consistent difference was the position of SCI. In particular, SCI was more similar to SCA based on outliers than nonoutliers, suggesting adaptive similarity between these populations. SNI was also very divergent from all other populations based on outliers identified using the top 5\% method and FDisT2 (Figs 7 and 8). Given extremely low genetic variation and small $N_{e}$ in SNI, this result could be an artefact of strong genetic drift causing fixation of alleles at many loci in SNI, such that these loci are identified as high $F_{\mathrm{ST}}$ outliers and SNI appears highly divergent from all other populations based on the outlier data set. In contrast, SNI was more similar to SCL based on outlier loci identified using BAYESFST (Figs S3-S6, Supporting information), suggesting SNI is most adaptively similar to SCL.

Interestingly, patterns of population similarity at high $F_{\mathrm{ST}}$ outlier loci were similar to patterns of similarity based on a suit of 29 morphometric (cranial and dentition) traits (Wayne et al. 1991). In particular, Wayne et al. (1991) found that, using these morphometric traits, SCI was most similar to SCA (the same pattern found here with high $F_{\mathrm{ST}}$ outliers) and that SNI was most similar to SCL (the same pattern found with high $F_{\mathrm{ST}}$ outliers identified using BAYESFST). The concordance between population similarity based on high $F_{\mathrm{ST}}$ outliers and morphology provides an independent line of evidence that high $F_{\mathrm{ST}}$ outliers or linked loci are under divergent selection and involved in adaptation. These high $F_{\mathrm{ST}}$ outlier loci or linked loci could underlie the actual morphological differences, or they could underlie other unmeasured, but correlated, traits also involved in adaptation to environmental heterogeneity among islands.

\section{Conservation implications}

Our results have several implications for island fox conservation and management. First, the high genetic differentiation we document, particularly at potentially adaptive, functional loci, coupled with previous studies documenting morphological differences among island fox populations (Grinnell et al. 1937; Wayne et al. 1991; Collins 1993), supports the current designation of each island fox population as a distinct subspecies. However, as we argue below, some circumstances might make it prudent for managers to consider supplementing a severely threatened subspecies with individuals from another subspecies, as has been done for Florida panthers (Puma concolor coryi; Hedrick 1995; Johnson et al. 2010).

Second, despite population rebounds on the northern islands and SCA following population crashes in the late 1990s, all island fox populations except SCL have very low genetic variation and small $N_{\mathrm{e}}$, suggesting that they remain vulnerable to the increase in frequency and expression of deleterious recessive alleles and to the loss of additive genetic variation. Managers should therefore strive to maintain large populations (e.g., at or close to carrying capacity) and avoid future population crashes, which could exacerbate these negative genetic effects. In addition, low genetic variation and small $N_{e}$ estimates documented here mean some populations may already be suffering from inbreeding depression (Ralls et al. 1979; Ralls \& Ballou 1983; Lacy 1997; Newman \& Pilson 1997; Saccheri et al. 1998). In particular, SNI has $<300$ adults (Table 1; Coonan 2015), a rapidly declining population $(\lambda=0.77)$, incredibly low genetic variation, and an extremely low $N_{\mathrm{e}}$ of 2.1; this population is highly vulnerable to extinction due to both demographic and genetic factors. We strongly recommend adjusting island fox monitoring programs to include tests for potential negative genetic effects in all subspecies. For example, genomic screening (e.g., Schwartz et al. 2007) would enable testing for variation in fitness related to inbreeding coefficients, average individual heterozygosity and genotypes at specific loci.

The adaptive differentiation among island fox populations that we document here and evidence that outbreeding depression is most likely in crosses between adaptively divergent populations (Edmands 2007; Frankham et al. 2011) might suggest that genetic rescue would have the unintended consequence of decreasing fitness, rather than the desired effect of reducing extinction risk. However, population genetic theory demonstrates that when $N_{e}$ is small, the threat of swamping out locally adapted alleles is low because strong genetic drift precludes the maintenance of many of these alleles in the first place (Wright 1931, 1951). Selection would have to be very strong for an adaptive allele to be maintained by selection with $N_{e}$ as small as observed in those island fox populations that would be the most likely candidates for genetic rescue. For example, on SNI with an $N_{\mathrm{e}}$ of 2.1, population genetic theory predicts that the selection coefficient would have to be $s>1 /\left(2 N_{\mathrm{e}}\right)=0.24$ to maintain an adaptive allele (Conner \& Hartl 2004), which is high relative to most empirical estimates of selection coefficients, at least for phenotypes (Conner 2001; Kingsolver et al. 2001). Moreover, if selection is this strong for a native, adaptive allele, then it is unlikely that a new, foreign, maladaptive allele will successfully "invade" and persist in the population. 
Thus, when $N_{e}$ is extremely small, as observed in some island fox populations, concerns about inbreeding depression may be more important than concerns about outbreeding depression. If a population has an unacceptably high probability of going extinct, inbreeding depression significantly contributes to this high extinction risk, and genetic rescue is predicted to reduce inbreeding depression, then genetic rescue should be considered as a viable management option (Tallmon et al. 2004; Hedrick \& Fredrickson 2010; Frankham 2015; Whiteley et al. 2015). Research is therefore critically needed to determine the viability of island fox populations, the magnitude of inbreeding depression, and potential fitness effects of interpopulation crosses and genetic rescue to determine if and when genetic rescue would be an effective management strategy. This research should be pursued as soon as possible so that these important management decisions can be made before population recovery is unlikely. Lessons from other systems - such as Isle Royale wolves (Canis lupus), Vancouver Island marmots (Marmota vancouverensis) and greater gliders (Petauroides volans) - highlight that waiting too long to make management decisions (and waiting too long to test the efficacy of management options) can cause imperiled populations to decline beyond the point of recovery (Lindenmayer et al. 2013; Marris 2015; Mlot 2015).

\section{Acknowledgements}

We thank Lisa Lyren, Erin Boydston, Francesca Ferrara, and many field assistants who helped collect blood and tissue samples, Tamara Max for helping prepare RAD libraries, and Brian Cypher for providing island fox diet data. We also thank Lisette Waits, Andrew R. Whiteley and three anonymous reviewers for providing helpful suggestions on the manuscript. This research was funded by the U.S. Department of Defense Legacy Resource Management Program, The Nature Conservancy, and the U.S. National Institutes of Health (grant number P30GM103324). This project was approved by the Institutional Animal Care and Use Committee at Colorado State University. Any use of trade, product, or firm names is for descriptive purposes only and does not imply endorsement by the U.S. Government.

\section{References}

Aguilar A, Roemer G, Debenham S et al. (2004) High MHC diversity maintained by balancing selection in an otherwise genetically monomorphic mammal. Proceedings of the National Academy of Sciences of the United States of America, 101, 3490-3494.

Baird NA, Etter PD, Atwood TS, et al. (2008) Rapid SNP discovery and genetic mapping using sequenced RAD markers. PLoS ONE, 3, e3376.

Balkenhol N, Waits LP, Dezzani RJ (2009) Statistical approaches in landscape genetics: an evaluation of methods for linking landscape and genetic data. Ecography, 32, 818-830.
Beaumont MA, Balding DJ (2004) Identifying adaptive genetic divergence among populations from genome scans. Molecular Ecology, 13, 969-980.

Beaumont MA, Nichols RA (1996) Evaluating loci for use in the genetic analysis of population structure. Proceedings of the Royal Society B-Biological Sciences, 263, 1619-1626.

Benjamini Y, Hochberg Y (1995) Controlling the false discovery rate: a practical and powerful approach to multiple testing. Journal of the Royal Statistical Society Series B-Methodological, 57, 289-300.

Bierne N, Roze D, Welch JJ (2013) Pervasive selection or is it..? why are FST outliers sometimes so frequent? Molecular Ecology, 22, 2061-2064.

Bryant D, Moulton V (2004) Neighbor-Net: an agglomerative method for the construction of phylogenetic networks. Molecular Biology \& Evolution, 21, 255-265.

Bürger R, Lynch M (1995) Evolution and extinction in a changing environment - a quantitative-genetic analysis. Evolution, 49, 151-163.

Burns KC (2007) Patterns in the assembly of an island plant community. Journal of Biogeography, 34, 760-768.

Catchen JM, Amores A, Hohenlohe P, Cresko W, Postlethwait JH (2011) STACKS: building and genotyping loci de novo from short-read sequences. Genes, Genomes, \& Genetics (G3), 1, 171182.

Catchen J, Hohenlohe PA, Bassham S, Amores A, Cresko WA (2013) STACKS: an analysis tool set for population genomics. Molecular Ecology, 22, 3124-3140.

Cayan DR, Maurer EP, Dettinger MD, Tyree M, Hayhoe K (2008) Climate change scenarios for the California region. Climatic Change, 87, S21-S42.

Collins PW (1993) Taxonomic and Biogeographic Relationships of the Island fox (Urocyon Littoralis) and Gray fox (Urocyon Cinereoargenteus) From Western North America. In: Third California Islands Symposium: Recent Advances in Research on the California Islands (ed. Hochberg FG), pp. 351-390. Santa Barbara Museum of Natural History, Santa Barbara, California.

Conner JK (2001) How strong is natural selection? Trends in Ecology \& Evolution, 16, 215-217.

Conner JK, Hartl DL (2004) A Primer of Ecological Genetics. Sinauer Associates, Inc., Sunderland, Massachusetts.

Cook BI, Ault TR, Smerdon JE (2015) Unprecedented 21st century drought risk in the American Southwest and Central Plains. Science Advances, 1, e1400082.

Coonan TJ (2015) Seventeenth annual meting, Island Fox Working Group, June 16-17, 2015, summary report. Available from http://www.mednscience.org/reports.

Coonan TJ, Schwemm CA, Garcelon DK (2010) Decline and Recovery of the Island Fox: A Case Study for Population Recovery. Cambridge University Press, Cambridge.

Cornuet JM, Luikart G (1996) Description and power analysis of two tests for detecting recent population bottlenecks from allele frequency data. Genetics, 144, 2001-2014.

Crandall KA, Bininda-Emonds ORP, Mace GM, Wayne RK (2000) Considering evolutionary processes in conservation biology. Trends in Ecology \& Evolution, 15, 290-295.

Cruickshank TE, Hahn MW (2014) Reanalysis suggests that genomic islands of speciation are due to reduced diversity, not reduced gene flow. Molecular Ecology, 23, 3133-3157.

Cypher BL, Madrid AY, Van Horn Job CL et al. (2014) Multipopulation comparison of resource exploitation by island 
foxes: implications for conservation. Global Ecology \& Conservation, 2, 255-266.

Do C, Waples RS, Peel D et al. (2014) NeEstimator v2: re-implementation of software for the estimation of contemporary effective population size $\left(N_{e}\right)$ from genetic data. Molecular Ecology Resources, 14, 209-214.

Earl DA, Vonholdt BM (2012) STRUCTURE HARVESTER: a website and program for visualizing STRUCTURE output and implementing the Evanno method. Conservation Genetics Resources, 4, 359-361.

Edmands S (2007) Between a rock and a hard place: evaluating the relative risks of inbreeding and outbreeding for conservation and management. Molecular Ecology, 16, 463-475.

Eldridge MDB, King JM, Loupis AK et al. (1999) Unprecedented low levels of genetic variation and inbreeding depression in an island population of the black-footed rockwallaby. Conservation Biology, 13, 531-541.

Emerson KJ, Merz CR, Catchen JM et al. (2010) Resolving postglacial phylogeography using high-throughput sequencing. Proceedings of the National Academy of Sciences of the United States of America, 107, 16196-16200.

Etter PD, Johnson EA (2012) RAD paired-end sequencing for local de novo assembly and SNP discovery in nonmodel organisms. In: Data Production and Analysis in Population Genomics: Methods and Protocols (eds Pompanon F, Bonin A), pp. 135-151. Humana Press, New York, New York.

Etter PD, Bassham S, Hohenlohe PA, Johnson EA, Cresko WA (2011) SNP discovery and genotyping for evolutionary genetics using RAD sequencing. In: Molecular Methods for Evolutionary Genetics (eds Orgogozo V, Rockamn MV), pp. 157178. Humana Press, New York, New York.

Evanno G, Regnaut S, Goudet J (2005) Detecting the number of clusters of individuals using the software STRUCTURE: a simulation study. Molecular Ecology, 14, 2611-2620.

Excoffier L, Laval G, Schneider S (2005) ARLEQUIN (version 3.0): an integrated software package for population genetics data analysis. Evolutionary Bioinformatics, 1, 47-50.

Fischer DT, Still CJ (2007) Evaluating patterns of fog water deposition and isotopic composition on the California Channel Islands. Water Resources Research, 43, W04420.

Fisher RA (1930) The Genetical Theory of Natural Selection. Clarendon Press, Oxford, UK.

Frankham R (1998) Inbreeding and extinction: Island populations. Conservation Biology, 12, 665-675.

Frankham R (2015) Genetic rescue of small inbred populations: meta-analysis reveals large and consistent benefits of gene flow. Molecular Ecology, 24, 2610-2618.

Frankham R, Ballou JD, Eldridge MDB et al. (2011) Predicting the probability of outbreeding depression. Conservation Biology, 25, 465-475.

Funk WC, McKay JK, Hohenlohe PA, Allendorf FW (2012) Harnessing genomics for delineating conservation units. Trends in Ecology E Evolution, 27, 489-496.

Gilbert DA, Lehman N, Obrien SJ, Wayne RK (1990) Genetic fingerprinting reflects population differentiation in the California Channel Island fox. Nature, 344, 764-767.

Goldstein DB, Roemer GW, Smith DA et al. (1999) The use of microsatellite variation to infer population structure and demographic history in a natural model system. Genetics, 151, 797-801.
Goslee SC, Urban DL (2007) The ecodist package for dissimilarity-based analysis of ecological data. Journal of Statistical Software, 22, 1-19.

Grant PR (1998) Evolution on Islands. Oxford University Press, Oxford.

Grant PR, Grant BR (2002) Unpredictable evolution in a 30-year study of Darwin's finches. Science, 296, 707-711.

Grinnell J, Dixon JS, Linsdale JM (1937) Fur-Bearing Mammals of California: Their Natural History, Systematic Status, and Relations to Man. University of California Press, Berkeley, California.

Heber S, Varsani A, Kuhn S et al. (2013) The genetic rescue of two bottlenecked South Island robin populations using translocations of inbred donors. Proceedings of the Royal Society B-Biological Sciences, 280, 2012-2228.

Hedrick PW (1995) Gene flow and genetic restoration: the Florida panther as a case study. Conservation Biology, 9, 996-1007.

Hedrick PW, Fredrickson R (2010) Genetic rescue guidelines with examples from Mexican wolves and Florida panthers. Conservation Genetics, 11, 615-626.

Hill WG (1981) Estimation of effective population size from data on genetic linkage disequilibrium. Genetical Research, 38, 209-216.

Hoeppner MP, Lundquist A, Pirun M et al. (2014) An improved canine genome and a comprehensive catalogue of coding genes and non-coding transcripts. PLoS ONE, 9, e91172.

Hofman CA, Rick TC, Hawkins MTR et al. (2015) Mitochondrial genomes suggest rapid evolution of dwarf California Channel Islands foxes (Urocyon littoralis). PLoS ONE, 10, e0118240.

Hohenlohe PA, Bassham S, Etter PD, et al. (2010a) Population genomics of parallel adaptation in threespine stickleback using sequenced RAD tags. PLoS Genetics, 6, e1000862.

Hohenlohe PA, Phillips PC, Cresko WA (2010b) Using population genomics to detect selection in natural populations: key concepts and methodological considerations. International Journal of Plant Sciences, 171, 1059-1071.

Hohenlohe PA, Day MD, Amish SJ et al. (2013) Genomic patterns of introgression in rainbow and westslope cutthroat trout illuminated by overlapping paired-end RAD sequencing. Molecular Ecology, 22, 3002-3013.

Huson DH, Bryant D (2006) Application of phylogenetic networks in evolutionary studies. Molecular Biology \& Evolution, 23, 254-267.

Johnson WE, Onorato DP, Roelke ME et al. (2010) Genetic restoration of the Florida panther. Science, 329, 1641-1645.

Jordan MA, Snell HL (2008) Historical fragmentation of islands and genetic drift in populations of Galápagos lava lizards (Microlophus albemarlensis complex). Molecular Ecology, 17, 1224-1237.

Jost L (2008) $G_{\mathrm{ST}}$ and its relatives do not measure differentiation. Molecular Ecology, 17, 4015-4026.

Kalinowski ST (2005) HP-RARE 1.0: a computer program for performing rarefaction on measures of allelic richness. Molecular Ecology Notes, 5, 187-189.

Kingsolver JG, Hoekstra HE, Hoekstra JM et al. (2001) The strength of phenotypic selection in natural populations. American Naturalist, 157, 245-261.

Kolbe JJ, Leal M, Schoener TW, Spiller DA, Losos JB (2012) Founder effects persist despite adaptive differentiation: a field experiment with lizards. Science, 335, 1086-1089. 
Lacy RC (1997) Importance of genetic variation to the viability of mammalian populations. Journal of Mammalogy, 78, 320-335.

LaDochy S, Witiw M (2012) The continued reduction in dense fog in the southern California region: possible causes. Pure $\mathcal{E}$ Applied Geophysics, 169, 1157-1163.

Legendre P, Lapointe FJ, Casgrain P (1994) Modeling brain evolution from behavior: a permutational regression approach. Evolution, 48, 1487-1499.

Lindenmayer DB, Piggott MP, Wintle BA (2013) Counting the books while the library burns: why conservation monitoring programs need a plan for action. Frontiers in Ecology and the Environment, 11, 549-555.

Losos JB, Jackman TR, Larson A, de Queiroz K, RodriguezSchettino L (1998) Contingency and determinism in replicated adaptive radiations of island lizards. Science, 279, 2115-2118.

Lotterhos KE, Whitlock MC (2014) Evaluation of demographic history and neutral parameterization on the performance of $F_{\mathrm{ST}}$ outlier tests. Molecular Ecology, 23, 2178-2192.

Lozier JD (2014) Revisiting comparisons of genetic diversity in stable and declining species: assessing genome-wide polymorphism in North American bumble bees using RAD sequencing. Molecular Ecology, 23, 788-801.

MacArthur RH, Wilson EO (1967) The Theory of Island Biogeography. Princeton University Press, Princeton, New Jersey.

Marris E (2015) Wolf decline threatens iconic island study. Nature, 520, 415.

Martínez-Solano I, Lawson R (2009) Escape to Alcatraz: evolutionary history of slender salamanders (Batrachoseps) on the islands of San Francisco Bay. BMC Evolutionary Biology, 9, 38.

McKay JK, Bishop JG, Lin JZ et al. (2001) Local adaptation across a climatic gradient despite small effective population size in the rare sapphire rockcress. Proceedings of the Royal Society B-Biological Sciences, 268, 1715-1721.

Mi HY, Muruganujan A, Thomas PD (2013) PANTHER in 2013: modeling the evolution of gene function, and other gene attributes, in the context of phylogenetic trees. Nucleic Acids Research, 41, D377-D386.

Mlot C (2015) Inbred wolf population on Isle Royale collapses. Science, 348, 383.

Nei M (1978) Estimation of average heterozygosity and genetic distance from a small number of individuals. Genetics, 89, 583-590.

Newman D, Pilson D (1997) Increased probability of extinction due to decreased genetic effective population size: experimental populations of Clarkia pulchella. Evolution, 51, 354-362.

Nosil P, Egan SP, Funk DJ (2008) Heterogeneous genomic differentiation between walking-stick ecotypes: "Isolation by adaptation" and multiple roles for divergent selection. Evolution, 62, 316-336.

Ordeñana MA, Crooks KR, Boydston EE et al. (2010) Effects of urbanization on carnivore species distribution and richness. Journal of Mammalogy, 91, 1322-1331.

Peakall R, Smouse PE (2006) GenAlEx 6: genetic analysis in Excel. Population genetic software for teaching and research. Molecular Ecology Notes, 6, 288-295.

Peakall R, Smouse PE (2012) GenAlEx 6.5: genetic analysis in Excel. Population genetic software for teaching and researchan update. Bioinformatics, 28, 2537-2539.

Piry S, Luikart G, Cornuet JM (1999) BOTTLENECK: a computer program for detecting recent reductions in the effective population size using allele frequency data. Journal of Heredity, 90, 502-503.

Pritchard JK, Stephens M, Donnelly P (2000) Inference of population structure using multilocus genotype data. Genetics, 155, 945-959.

Pujolar JM, Jacobsen MW, Frydenberg J et al. (2013) A resource of genome-wide single-nucleotide polymorphisms generated by RAD tag sequencing in the critically endangered European eel. Molecular Ecology Resources, 13, 706-714.

R Development Core Team (2010) R: A Language and Environment for Statistical Computing. R Foundation for Statistical Computing, Vienna, Austria. Available from http:// www.Rproject.org/

Ralls K, Ballou J (1983) Extinction: lessons from zoos. In: Genetics and Conservation (eds Schonewald-Cox C, Chambers S, MacBryde B, Thomas L), pp. 164-184. Benjamin/Cummings, Menlo Park, California.

Ralls K, Brugger K, Ballou J (1979) Inbreeding and juvenile mortality in small populations of ungulates. Science, 206, 1101-1103.

Rick TC, Erlandson JM, Vellanoweth RL et al. (2009) Origins and antiquity of the island fox (Urocyon littoralis) on California's Channel Islands. Quaternary Research, 71, 93-98.

Robertson JM, Langin KM, Sillett TS, Morrison SA, Ghalambor CK, Funk WC (2014) Identifying Evolutionarily Significant Units and prioritizing populations for management on islands. Monographs of the Western North American Naturalist, 7, 397-411.

Roemer GW, Coonan TJ, Garcelon DK, Bascompte J, Laughrin L (2001) Feral pigs facilitate hyperpredation by golden eagles and indirectly cause the decline of the island fox. Animal Conservation, 4, 307-318.

Roesti M, Hendry AP, Salzburger W, Berner D (2012) Genome divergence during evolutionary diversification as revealed in replicate lake-stream stickleback population pairs. Molecular Ecology, 21, 2852-2862.

Ryder OA (1986) Species Conservation and systematics - the dilemma of subspecies. Trends in Ecology \& Evolution, 1, 9-10.

Saccheri I, Kuussaari M, Kankare M et al. (1998) Inbreeding depression and extinction in a butterfly metapopulation. Nature, 392, 491-494.

Schwartz MK, Luikart G, Waples RS (2007) Genetic monitoring as a promising tool for conservation and management. Trends in Ecology \& Evolution, 22, 25-33.

Spalding MD, Fox HE, Halpern BS et al. (2007) Marine ecoregions of the world: a bioregionalization of coastal and shelf areas. BioScience, 57, 573-583.

Stuart YE, Losos JB, Algar AC (2012) The island-mainland species turnover relationship. Proceedings of the Royal Society B-Biological Sciences, 279, 4071-4077.

Tallmon DA, Luikart G, Waples RS (2004) The alluring simplicity and complex reality of genetic rescue. Trends in Ecology $\mathcal{E}$ Evolution, 19, 489-496.

Timm SF, Munson L, Summers BA et al. (2009) A suspected canine distemper epidemic as the cause of a catastrophic decline in Santa Catalina Island foxes (Urocyon littoralis catalinae). Journal of Wildlife Diseases, 45, 333-343.

U.S. Fish and Wildlife Service (2004) Listing of the San Miguel island fox, Santa Rosa island fox, Santa Cruz island fox, and Santa Catalina island fox as endangered; final rule. Federal Register, 69, 10335-10353. 
Verity R, Nichols RA (2014) What is genetic differentiation, and how should we measure it: $G_{\mathrm{ST}}, D$, neither or both? Molecular Ecology, 23, 4216-4225.

Villemereuil P, Gaggiotti OE (2015) A new $F_{\mathrm{ST}^{-}}$-based method to uncover local adaptation using environmental variables. Methods in Ecology \& Evolution, 6, 1248-1258.

Waples RS (2005) Genetic estimates of contemporary effective population size: to what time periods do the estimates apply? Molecular Ecology, 14, 3335-3352.

Waples RS (2010) Spatial-temporal stratifications in natural populations and how they affect understanding and estimation of effective population size. Molecular Ecology Resources, 10, 785-796.

Wayne RK, George SB, Gilbert D et al. (1991) A morphological and genetic study of the island fox, Urocyon littoralis. Evolution, 45, 1849-1868.

Weigelt P, Jetz W, Kreft H (2013) Bioclimatic and physical characterization of the world's islands. Proceedings of the National Academy of Sciences of the United States of America, 110, 15307-15312.

Whiteley AR, Hastings K, Wenburg JK et al. (2010) Genetic variation and effective population size in isolated populations of coastal cutthroat trout. Conservation Genetics, 11, 1929-1943.

Whiteley AR, Fitzpatrick SW, Funk WC, Tallmon DA (2015) Genetic rescue to the rescue. Trends in Ecology \& Evolution, 30, 42-49.

Willing E-M, Bentzen P, van Oosterhout C et al. (2010) Genome-wide single nucleotide polymorphisms reveal population history and adaptive divergence in wild guppies. Molecular Ecology, 19, 968-984.

Wright S (1931) Evolution in Mendelian populations. Genetics, 16, 97-159.

Wright S (1951) The genetical structure of populations. Annals of Eugenics, 15, 323-354.

W.C.F., R.E.L., P.A.H., C.A.H. S.A.M., T.S.S., C.K.G., J.E.M., and T.C.R: Research concept and design; T.J.C., K.R.C., A.D., D.K.G., J.L.K., C.L.B., N.G., and W.F.A: Sample collection; W.C.F., P.A.H., M.D.D. N.R.P., and S.W.F: Data analysis and interpretation; W.C.F: Writing the article; All authors: Critical revision and final approval of the article.

\section{Data accessibility}

Raw sequence data, RAD contig sequences and genotype data: Dryad doi:10.5061/dryad.2kn1v.

\section{Supporting information}

Additional supporting information may be found in the online version of this article.

Fig. S1 Frequency histogram of mean coverage per locus averaged across individuals for the SNP data set including grey foxes.

Fig. S2 Frequency histogram of mean number of loci per individual for the SNP data set including grey foxes (total number of SNP loci was 4858).

Fig. S3 Principle component analysis (PCA) with grey foxes using ( $a, c$, e, and g) presumably neutral SNPs not identified as high $F_{\mathrm{ST}}$ outliers or $(\mathrm{b}, \mathrm{d}, \mathrm{f}$ and $\mathrm{h}$ ) presumably adaptive SNPs identified as high $F_{\mathrm{ST}}$ outliers.

Fig. S4 Principle component analysis (PCA) without grey foxes using ( $a, c$, e and g) presumably neutral SNPs not identified as high $F_{\mathrm{ST}}$ outliers or $(\mathrm{b}, \mathrm{d}, \mathrm{f}$ and $\mathrm{h}$ ) presumably adaptive SNPs identified as high $F_{\mathrm{ST}}$ outliers.

Fig. S5 Neighbour-net trees with grey foxes using ( $a, b, c$ and d) presumably neutral SNPs not identified as high $F_{\mathrm{ST}}$ outliers or (e, $\mathrm{f}, \mathrm{g}$, and $\mathrm{h}$ ) presumably adaptive SNPs identified as high $F_{\mathrm{ST}}$ outliers.

Fig. S6 Neighbour-net trees without grey foxes using (a, b, c and d) presumably neutral SNPs not identified as high $F_{\mathrm{ST}}$ outliers or (e, $\mathrm{f}, \mathrm{g}$ and $\mathrm{h}$ ) presumably adaptive SNPs identified as high $F_{\mathrm{ST}}$ outliers. Outlier loci were identified using (a and e) the highest $5 \%$ of $F_{\mathrm{ST}}$ values, ( $\mathrm{b}$ and $\mathrm{f}$ ) FDIST2, (c and g) FDIST2 with a false discovery rate (FDR) correction, or ( $\mathrm{d}$ and $\mathrm{h}$ ) BAYESFST.

Table S1 High $F_{\mathrm{ST}}$ outlier loci that blasted to genes in the dog genome. 